\title{
Electron Beam Synthesis and Characterization of Acrylamide/Acrylic Acid Hydrogels Using Trimethylolpropane Trimethacrylate as Cross-Linker
}

\author{
Gabriela Craciun, ${ }^{1}$ Elena Manaila, ${ }^{1}$ and Maria Daniela Stelescu ${ }^{2}$ \\ ${ }^{1}$ National Institute for Laser, Plasma and Radiation Physics, Electron Accelerators Laboratory, 409 Atomistilor Street, \\ 077125 Magurele, Romania \\ ${ }^{2}$ Leather and Footwear Research Institute, National R\&D Institute for Textile and Leather, 93 Ion Minulescu Street, \\ 031215 Bucharest, Romania \\ Correspondence should be addressed to Maria Daniela Stelescu; dmstelescu@yahoo.com
}

Received 15 November 2015; Accepted 16 February 2016

Academic Editor: Barbara Gawdzik

Copyright (C) 2016 Gabriela Craciun et al. This is an open access article distributed under the Creative Commons Attribution License, which permits unrestricted use, distribution, and reproduction in any medium, provided the original work is properly cited.

\begin{abstract}
The purpose of the paper is to present the synthesis and characterization of hydrogels prepared by free-radical copolymerization of acrylamide and acrylic acid in aqueous solutions using potassium persulfate as initiator and trimethylolpropane trimethacrylate as cross-linker, via the radiation technique. The samples were subjected to electron beam treatment in the dose range of 2 to $4 \mathrm{kGy}$ and the influence of the absorbed dose and amount of cross-linker on the swelling properties, diffusion coefficient, and network parameters of hydrogels was investigated. A possible reaction mechanism for acrylamide/acrylic acid/trimethylolpropane trimethacrylate hydrogels was also suggested. The structure and morphology of hydrogels were characterized by Fourier Transform Infrared Spectroscopy and Scanning Electron Microscopy.
\end{abstract}

\section{Introduction}

Hydrogels are three-dimensionally cross-linked hydrophilic polymers capable of swelling and retaining huge volume in the swollen state, even under pressure. These macromolecule networks can absorb water, many hundreds of times more than their dried weight. Due to their unique characteristics like hydrophilicity, swelling in aqueous media, nonsoluble nature in aqueous fluids, and ionic aspects, they are applied in biomedicine, bioengineering, pharmaceutical, food industry, or agriculture [1-3]. Because of their excellent response to changing of the environment conditions such as temperature, $\mathrm{pH}$, and solvent composition, hydrogel particles distributed in soil are capable of absorbing water and then slowly releasing it from the polymeric matrix [1, 4]. Hydrogels are broadly classified into two categories: permanent or chemical gel and reversible or physical gel. Permanent or chemical gel is a covalently cross-linked network obtained by replacing hydrogen bond with a stronger and stable covalent bond $[5,6]$. They reach an equilibrium swelling state which depends on the polymer-water interaction parameter and the cross-link density [5,7]. In the reversible or physical gel, the networks are held together by molecular entanglements and/or secondary forces including ionic, hydrogen bonding or hydrophobic interactions. In the physically cross-linked gels, dissolution is prevented by physical interactions which exist between different polymer chains $[5,7]$.

The various techniques adopted for hydrogels preparation are the physical and chemical cross-linking, the grafting polymerization, and the radiation cross-linking $[5,8-10]$. The initiation of chemical reactions by using radiation is increasingly used for novel hydrogels obtaining. The radiation technique is more preferable than the chemical one, because of the advantage offered by the gentle control of cross-linking level by variation of the absorbed dose. It is a simple additive-free process which is happening at any temperature; the reactions such as polymerization, crosslinking, and grafting can be easily controlled and the treatment can be limited to a specific area [11]. The processing of 
TABLE 1: Thematerials used for the preparation of the hydrogels.

\begin{tabular}{|c|c|c|}
\hline Materials & $\begin{array}{l}\text { Chemical } \\
\text { characteristics }\end{array}$ & Chemical structure \\
\hline Acrylamide (AMD) & $\begin{array}{l}\text { (i) Molecular weight: } 71.08 \mathrm{~g} / \mathrm{mol} \\
\text { (ii) Density: } 1.13 \mathrm{~g} / \mathrm{cm}^{3} \\
\text { (iii) Melting point: } 84.5^{\circ} \mathrm{C} \\
\text { (iv) Solubility in water: } 2.04 \mathrm{~kg} / \mathrm{L} \text { at } 25^{\circ} \mathrm{C}\end{array}$ & $\mathrm{H}_{2} \mathrm{C}=\mathrm{CH}-\mathrm{C}^{3}$ \\
\hline Acrylic acid (AA) & $\begin{array}{l}\text { (i) Molecular weight: } 72.06 \mathrm{~g} / \mathrm{mol} \\
\text { (ii) Density: } 1.051 \mathrm{~g} / \mathrm{cm}^{3} \\
\text { (iii) Melting point: } 14^{\circ} \mathrm{C} \\
\text { (iv) Boiling point: } 141^{\circ} \mathrm{C} \\
\text { (v) Solubility in water: miscible }\end{array}$ & $\mathrm{H}_{2} \mathrm{C}=\mathrm{CH}-\mathrm{C}$ \\
\hline $\begin{array}{l}\text { Potassium persulfate } \\
\text { (PP) }\end{array}$ & $\begin{array}{l}\text { (i) Molecular weight: } 270.322 \mathrm{~g} / \mathrm{mol} \\
\text { (ii) Density: } 2.477 \mathrm{~g} / \mathrm{cm}^{3} \\
\text { (iii) Melting point: } 14^{\circ} \mathrm{C} \\
\text { (iv) Boiling point: } 141^{\circ} \mathrm{C} \\
\text { (v) Solubility in water: } 1.75 \mathrm{~g} / 100 \mathrm{~mL} \text { at } 0^{\circ} \mathrm{C}\end{array}$ & $\mathrm{K}_{2} \mathrm{~S}_{2} \mathrm{O}_{8}$ \\
\hline $\begin{array}{l}\text { Trimethylolpropane } \\
\text { trimethacrylate } \\
\text { (TMPT) }\end{array}$ & $\begin{array}{l}\text { (i) Molecular weight: } 338.4 \mathrm{~g} / \mathrm{mol} \\
\text { (ii) Boiling point: }>200^{\circ} \mathrm{C} \\
\text { (iii) Density: } 1.06 \mathrm{~g} / \mathrm{cm}^{3} \\
\text { (iv) } 75 \pm 3 \% \text { active ingredient }\end{array}$ & 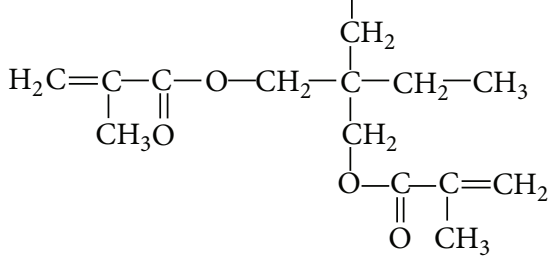 \\
\hline
\end{tabular}

materials by irradiation with accelerated electrons removes many drawbacks of the conventional technologies, because ionizing radiation initiates polymerization without thermal input from the outside, due to free radicals that are formed at the interaction with the monomers and especially with the solvent (water in this case). So, a good solution to produce polymeric materials is to use ionizing radiation and especially electron beams, which direct their energy in the entire volume of the monomeric solutions to be irradiated.

The purpose of this study is to present the synthesis and characterization of some hydrogels prepared by freeradical copolymerization of acrylamide and acrylic acid in aqueous solutions using potassium persulfate as initiator and trimethylolpropane trimethacrylate as cross-linker. The free-radical copolymerization was realized by electron beam irradiation in the dose range of 2 to $4 \mathrm{kGy}$ in atmospheric conditions and at room temperature. The cross-linker was used in conjunction with the radical cure systems in order to improve physical properties of the final product. A possible reaction mechanism is proposed. The obtained hydrogels were investigated through swelling and diffusion experiments and also using the infrared spectroscopy in order to evaluate the chemical structure of the obtained networks. The surface appearance was also observed using the technique of Scanning Electron Microscopy.

\section{Experimental}

2.1. Materials. The materials used for the obtaining of hydrogels are shown in Table 1: acrylamide (AMD) and acrylic acid (AA) as comonomers, potassium persulfate (PP) as initiator, and trimethylolpropane trimethacrylate (TMPT) as cross-linker. All reagents were obtained from LACHEMA, Germany, and were used directly, without purification.

Other chemicals used in this study for physical and chemical characterization of the hydrogels were of analytical grade.

2.2. Experimental Installation and Sample Preparation. The experiments were carried out using the electron linear accelerator called ALIN 10 from the National Institute for Laser, Plasma and Radiation Physics. The ALIN 10 linear accelerator is a travelling-wave type, operating at a wavelength of $10 \mathrm{~cm}$ and having $164 \mathrm{~W}$ maximum output power. The accelerating structure is a disk-loaded tube, which operates in the $\pi / 2$ mode. The optimum values of the electron beam, peak current $I_{\mathrm{EB}}$ and EB energy $E_{\mathrm{EB}}$ to produce maximum output power $P_{\mathrm{EB}}$ for a fixed pulse duration $\tau_{\mathrm{EB}}$ and repetition frequency $f_{\mathrm{EB}}$, are as follows: $E_{\mathrm{EB}}=6.23 \mathrm{MeV}, I_{\mathrm{EB}}=75 \mathrm{~mA}$, and $P_{\mathrm{EB}}=164 \mathrm{~W}\left(f_{\mathrm{EB}}=100 \mathrm{~Hz}, \tau_{\mathrm{EB}}=3.5 \mu \mathrm{s}\right)$. The $\mathrm{EB}$ effects are related to the absorbed dose $(D)$ and absorbed dose rate $\left(D^{*}\right)$. The absorbed dose is the major parameter in the electron beam (EB) irradiation [12]. The performances of polymerization and copolymerization processes are provided by the strict control of this parameter [12]. In our experiments the electron beam dose rate was fixed at $2 \mathrm{kGy} / \mathrm{min}$, in order to accumulate doses between 2 and $4 \mathrm{kGy}$. The absorbed dose was determined using the conventional Fricke dosimeter. The thickness of $2.5 \mathrm{~cm}$ of the irradiated samples was established in accordance with the samples densities (of about $1 \mathrm{~g} \mathrm{~cm}^{-3}$ 
TABLE 2: The hydrogels synthesis details.

\begin{tabular}{|c|c|c|c|c|c|}
\hline \multirow{2}{*}{ Samples codes } & \multicolumn{4}{|c|}{ Amount of chemicals $(\mathrm{mol} / \mathrm{L})$} & \multirow{2}{*}{ Irradiation dose (kGy) } \\
\hline & AMD & AA & $\mathrm{PP}$ & TMPT & \\
\hline $\mathrm{H}_{1-1}, \mathrm{H}_{1-2}, \mathrm{H}_{1-3}$ & 5 & 0.5 & $3.70 \times 10^{-3}$ & $2.95 \times 10^{-3}$ & $2,3,4$ \\
\hline $\mathrm{H}_{2-1}, \mathrm{H}_{2-2}, \mathrm{H}_{2-3}$ & 5 & 0.5 & $3.70 \times 10^{-3}$ & $5.90 \times 10^{-3}$ & $2,3,4$ \\
\hline
\end{tabular}

in our case) and EB energy. For irradiation, two types of aqueous solutions were prepared (Table 2). The solutions were placed in polyvinylchloride (PVC) containers of $3 \mathrm{~cm}$ diameter and irradiated in atmospheric conditions and at room temperature of $25^{\circ} \mathrm{C}$ with $2 \mathrm{kGy}, 3 \mathrm{kGy}$, and $4 \mathrm{kGy}$. After irradiation, the obtained hydrogels were cut into pieces of $3 \pm 4 \mathrm{~mm}$ length, dried in air for 3 days and in a laboratory oven at $50^{\circ} \mathrm{C}$ for 12 hours to constant weight, and then stored in desiccators. The dried hydrogels were used to determine the parameters of swelling, diffusion, and network.

\subsection{Sample Characterization}

2.3.1. Fourier Transform Infrared (FTIR) Spectroscopy Anal$y$ sis. In order to obtain spectral information regarding the chemical structure of hydrogels, a FTIR spectrophotometer, JASCO FT/IR 4200, was used by ATR measurement method. Samples spectra are the average of 30 scans realized in absorption, in the range of $4000-600 \mathrm{~cm}^{-1}$, with a resolution of $4 \mathrm{~cm}^{-1}$.

2.3.2. Experiments of Swelling and Diffusion. The swelling of dried hydrogels was carried out by immersion in doubly distilled water at $25 \pm 0.1^{\circ} \mathrm{C}$ in a water bath, in order to determine the parameters of swelling and diffusion. The amount of absorbed water was determined by weighing the samples, after wiping with filter paper, at various time intervals. The swollen hydrogels were weighed using an electronic balance (HR 200, $0.1 \mathrm{mg}$ resolution).

2.3.3. Scanning Electron Microscopy (SEM). The morphology of the lyophilized hydrogels was determined using a scanning electron microscope (FEI/Phillips, USA). Small pieces of swelled gels were freeze-dried in order to avoid the collapse of porous structure. Freeze-drying was carried out in vacuum at $-80^{\circ} \mathrm{C}$ for $40 \mathrm{~h}$ using the Christ Alfa 2-4 (Martin Christ, Germany) lyophilizer. For scanning, the lyophilized samples have been cut in order to expose the inner surface. Samples were placed on an aluminum mount, sputtered with gold palladium, and then scanned at an accelerating voltage up to $30 \mathrm{kV}$.

\section{Results and Discussion}

3.1. Synthesis and Reaction Mechanism Aspects. In our study, the $\mathrm{EB}$ radiation technique was used in order to prepare AMD/AA hydrogels in the presence of TMPT as crosslinker. The initiating of chemical reactions by irradiation is usually done using ionizing radiations with energies ranging from 0.5 to $10 \mathrm{MeV}$. Radio-induced polymerization is quite

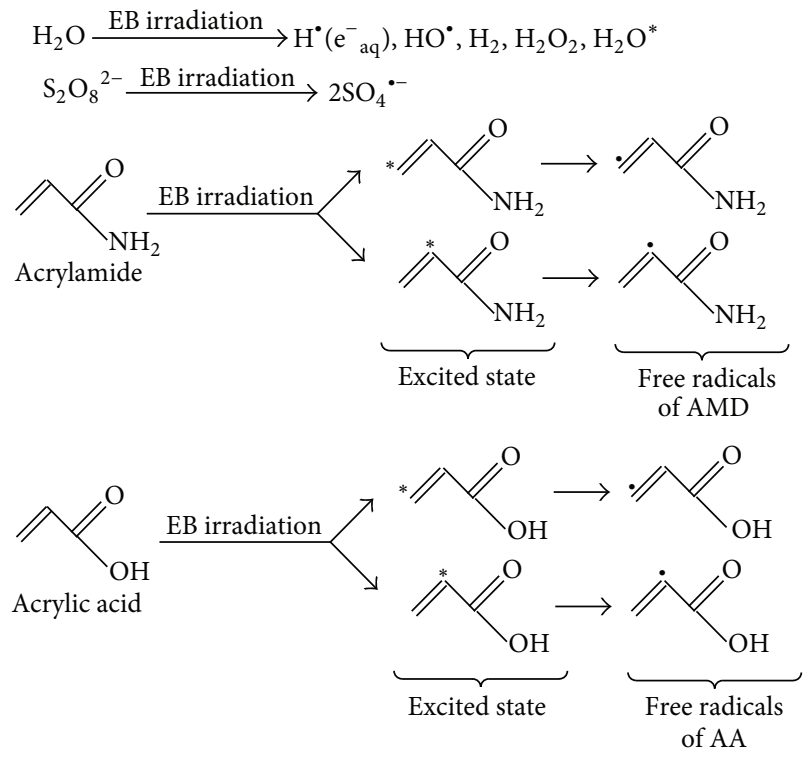

SCHEME 1: The scheme of possible reaction mechanism for obtaining free radicals by electron beam irradiation from a system formed of water, potassium persulphate, and monomers (acrylamide and acrylic acid).

similar to classic polymerization through addition of free radicals. The initial phase of polymerization involves, in both types of polymerizations, classic and induced by ionizing radiations, the introducing of a certain amount of energy in the system, the initiating energy. In the case of radioinduced polymerization, the initiating energy is introduced by ionizing radiation and involves the radical formation. The advantage of radio-induced copolymerization is that the radicals can be formed by decomposition of all components of the system: solvent (in this case, water), initiator, and monomers [12-14]. A possible reaction mechanism for obtaining free radicals by electron beam irradiation from a system formed of water, potassium persulphate, and monomers (acrylamide and acrylic acid) is given in Scheme 1.

The main function of the ionizing radiation is to achieve the first step of the polymerization process: the initiation phase leading to free radical formation and to some specific side effects. The next polymerization phases, propagation, completion, and the chain transfer process, occur almost identically as in classic polymerization processes. Based on our results and literature studies $[2,15]$, a possible reaction mechanism for the copolymerization of acrylamide and acrylic acid by electron beam irradiation is proposed in Scheme 2. 


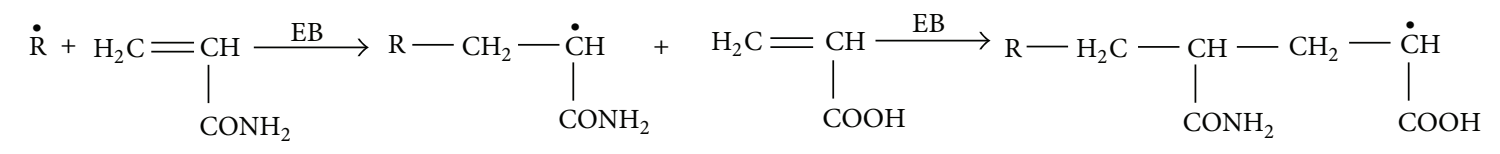

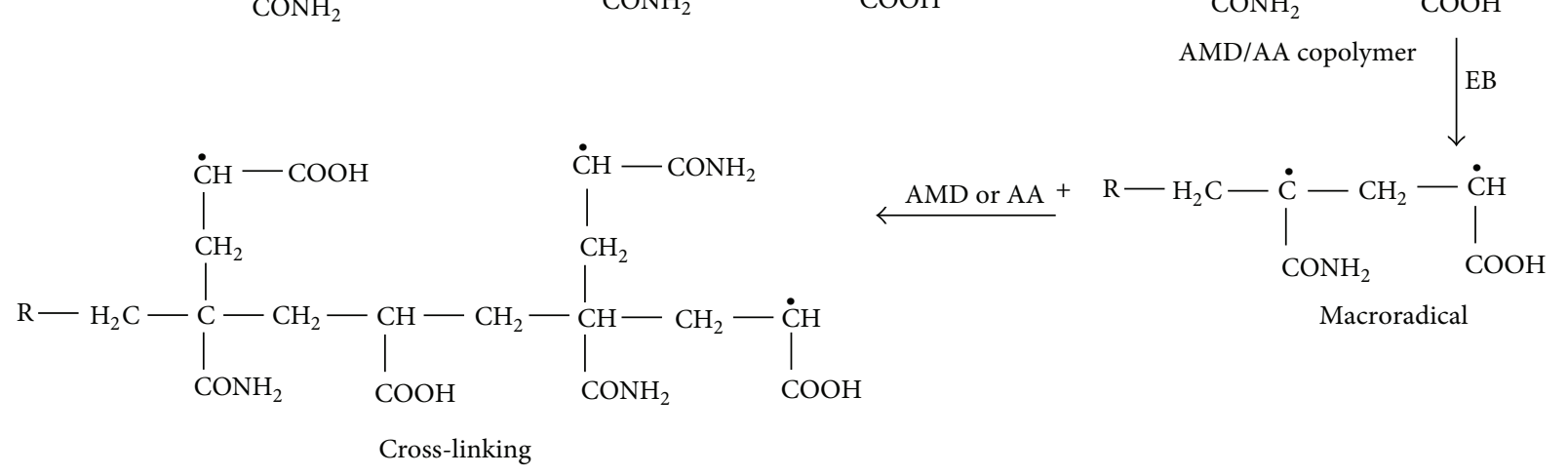

Scheme 2: The scheme of a possible reaction mechanism for obtaining hydrogels based on acrylamide and acrylic acid in the presence of free radicals formed by water radiolysis or initiator decomposition.

The cross-linkers are usually used in conjunction with the radical cure systems in order to promote cross-linking reactions and to improve the physical properties. They are typically polyfunctional monomers and are effective in modification of materials not only by cross-linking but also by grafting and radical addition. The addition of an appropriate polyfunctional monomer in the polymer matrix may lead to the obtaining of a desired cross-linking density even at lower absorbed doses. By increasing the cross-link density, the network performance can be improved also. There are two important classes in which the polyfunctional monomers can be grouped, according to their influence on cure kinetics or to their physical properties. The polyfunctional monomers of type I are highly reactive and very effective for the increasing of both rate and state of cure (acrylate, methacrylate, or maleimide functionality). The polyfunctional monomers of type II are based on allyl reactive sites and increase the state of cure only. In order to obtain hydrogels with improved network characteristics and good physicochemical properties we used TMPT (a polyfunctional monomer of Type I) as cross-linker.

It is suggested that the polymerization reaction of AMD/AA in presence of TMPT can be depicted as a two-step process: in the first step, a rapid initial polymerization of the polyfunctional monomer occurs and in the second step the reaction between the polymerized polyfunctional monomer and the AMD/AA chains takes place in order to form a crosslinked AMD/AA-TMPT network [16, 17]. Scheme 3 presents a possible reaction mechanism between AMD/AA chains in the presence of TMPT which occurs in EB cross-linking.

3.2. Spectral Characterization. The infrared spectroscopy was carried out in order to investigate the chemical structure of the obtained hydrogels and the results presented in Figures 1 and 2 were obtained in absorbance in the range of $4000-$ $650 \mathrm{~cm}^{-1}$.

The broad bands in the range of 3345 to $3330 \mathrm{~cm}^{-1}$ are attributed to the symmetric and asymmetric $-\mathrm{NH}$ stretching vibrations of $A M D$ and the broad bands in the region of
$3200-3190 \mathrm{~cm}^{-1}$ are characteristic for the absorptions of $-\mathrm{OH}$ groups of AA. The methylene group vibrations are used to monitor the extent of polymerization. The absorbance in the range of $2937-2933 \mathrm{~cm}^{-1}$ is assigned to the asymmetrical stretching vibrations of $-\mathrm{CH}_{2}$ from AMD or AA [18, 19]. The bands in the range of $1774-1785 \mathrm{~cm}^{-1}$ correspond to the carbonyl stretching vibration of $\mathrm{C}=\mathrm{O}$ connected to the carboxyl group but in the range of $1647-1657 \mathrm{~cm}^{-1}$ can be attributed to the $\mathrm{C}=\mathrm{O}$ group connected to the amide group [18]. The characteristic band which appeared in the range of $1600-1620 \mathrm{~cm}^{-1}$ is due to the amide II bands. Amide II results from the $\mathrm{N}-\mathrm{H}$ bending vibration and from the C$\mathrm{N}$ stretching vibration. Symmetric stretching of $\mathrm{COO}^{-}$is found at $1450-1410 \mathrm{~cm}^{-1}$ in poly(acrylamide-co-acrylic acid) spectra [18]. On the other hand, the bands at $1443 \mathrm{~cm}^{-1}$ and $1353 \mathrm{~cm}^{-1}$ are attributed to the $\mathrm{CH}_{2}$ bending and $\mathrm{CH}$ bending vibrations, respectively. For the polyacrylamide, the $-\mathrm{CN}$ stretching appears at $1350-1345 \mathrm{~cm}^{-1}$ and $-\mathrm{C}-$ $\mathrm{O}$ stretching at $1125-1116 \mathrm{~cm}^{-1}$. The $\mathrm{C}-\mathrm{O}-\mathrm{C}$ asymmetric stretching and $\mathrm{C}-\mathrm{O}$ stretching from $\mathrm{AA}$ are confirmed with the absorptions around $1190-1180 \mathrm{~cm}^{-1}$ and $1065-1025 \mathrm{~cm}^{-1}$, respectively [20].

\subsection{Swelling and Diffusion Experiments}

3.3.1. The Measurement of Gel Fraction. Normally, the hydrogel content of a given material is estimated by measuring its insoluble part in dried sample after immersion in water. In order to determine the gel fraction and the soluble fraction in the obtained hydrogels, dried samples of $0.05 \mathrm{~g}$ were immersed in double distilled water in order to swell for $72 \mathrm{~h}$ [4]. After filtration, the extracted gel was dewatered by nonsolvent ethanol, dried in air and then to constant weight in a laboratory oven for $5 \mathrm{~h}$ at $50^{\circ} \mathrm{C}$, and finally reweighed. The gel fraction and soluble fraction were determined as follows [21]:

$$
\begin{aligned}
& \text { Sol_fraction }(\%)=\frac{W_{0}-W_{1}}{W_{0}} \times 100, \\
& \text { Gel_fraction }(\%)=100-\text { Sol_fraction, }
\end{aligned}
$$




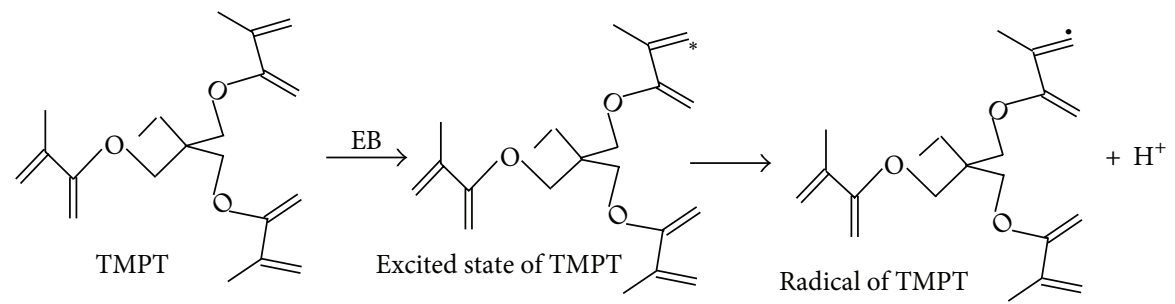

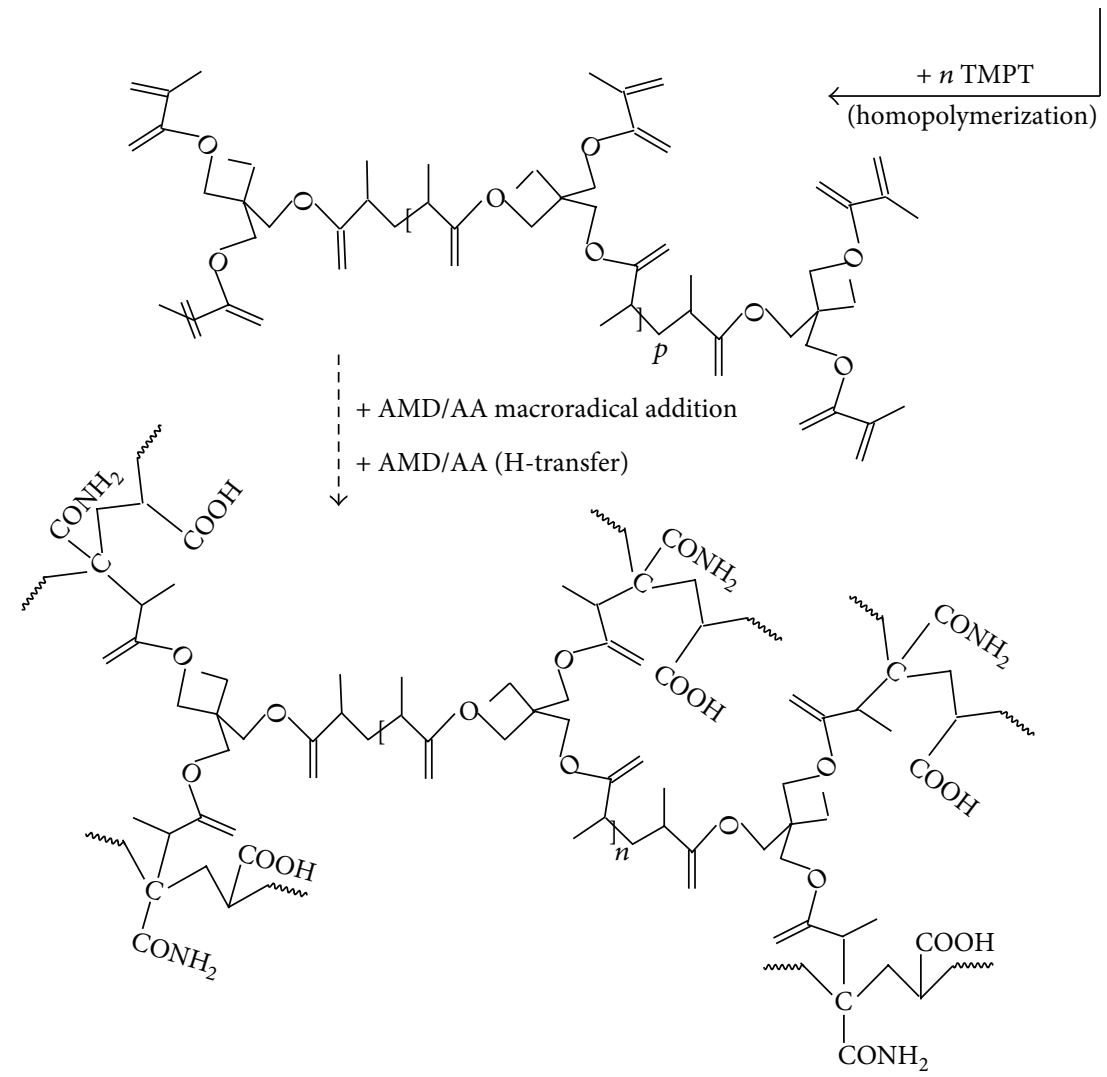

SCHEME 3: The scheme of a possible reaction mechanism between AMD/AA and TMPT in EB cross-linking.

where $W_{0}$ is the initial weight of the dried sample and $W_{1}$ is the weight of sample after extraction from the water and drying.

Figure 3 shows the effect of the absorbed dose and amount of TMPT on the gel fraction and soluble fraction of hydrogels. It was found that the gel fraction depends on the concentration of TMPT, increases with radiation dose increasing, and attains a maximum at the radiation dose of 4 kGy.

3.3.2. Swelling Measurements. On the cross-linked AMD/ AA/TMPT hydrogels, the dynamic swelling experiments were performed in distilled water, at room temperature $(25 \pm$ $0.1^{\circ} \mathrm{C}$ ), and the mass increasing was pursued as a function of time. A fundamental relationship exists between the swelling of a polymer in a solvent and the nature of polymer and solvent. The swelling $S$, expressed in percentages, was calculated from the following relation $[15,22]$ :

$$
S(\%)=\frac{M_{t}-M_{0}}{M_{0}} \times 100,
$$

where $M_{t}$ is the mass of the swollen gel at time $t$ and $M_{0}$ is the initial mass of the dried gel (at time $t=0$ ).

The water intake of initially dried hydrogels was pursued for a long period of time. The hydrogels swelling isotherms, as a function of the absorbed dose and the amount of crosslinker, are shown in Figure 4.

It can be seen that the swelling increases with the increase of the TMPT amount at the same absorbed dose, until a certain point when it becomes constant. It can be noticed that, for the sample which contains a higher amount of TMPT $\left(5.90 \times 10^{-3} \mathrm{~mol} / \mathrm{L}\right)$ even at the highest irradiation dose (4 kGy), the swelling is around $3900 \%$, compared with 


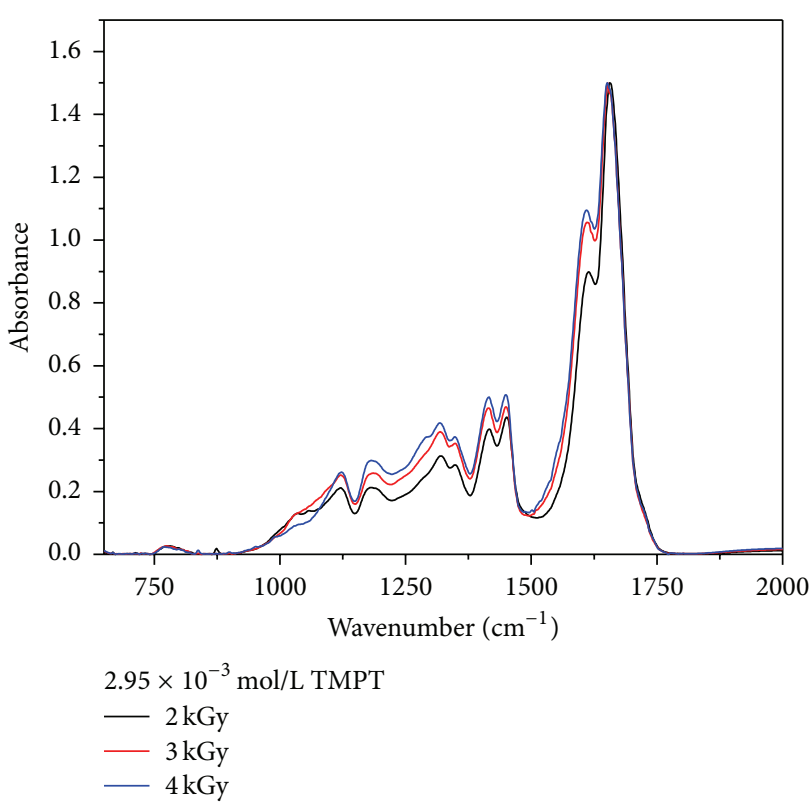

(a)

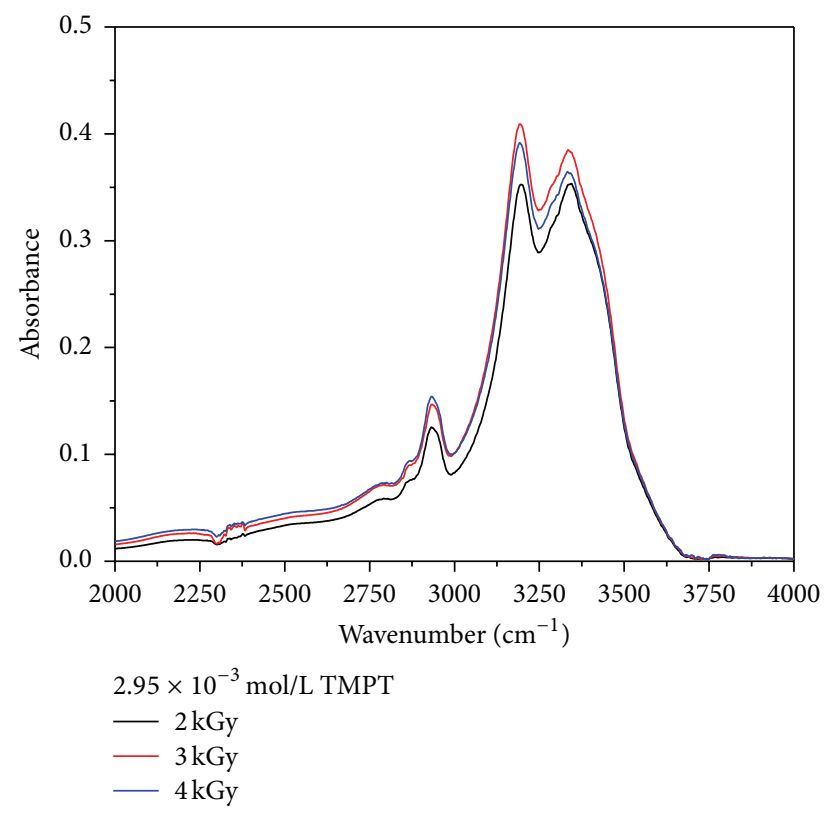

(b)

FIGURE 1: FTIR spectra for hydrogels having $2.95 \times 10^{-3} \mathrm{~mol} / \mathrm{L}$ TMPT, in the range of (a) $750-2000 \mathrm{~cm}^{-1}$ and (b) $2000-4000 \mathrm{~cm}^{-1}$.

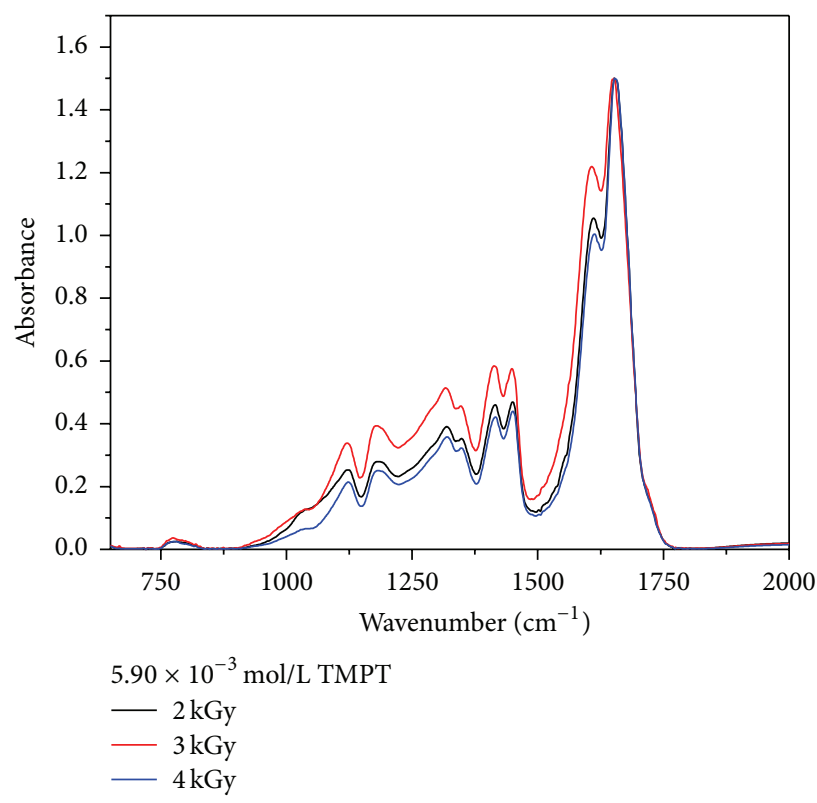

(a)

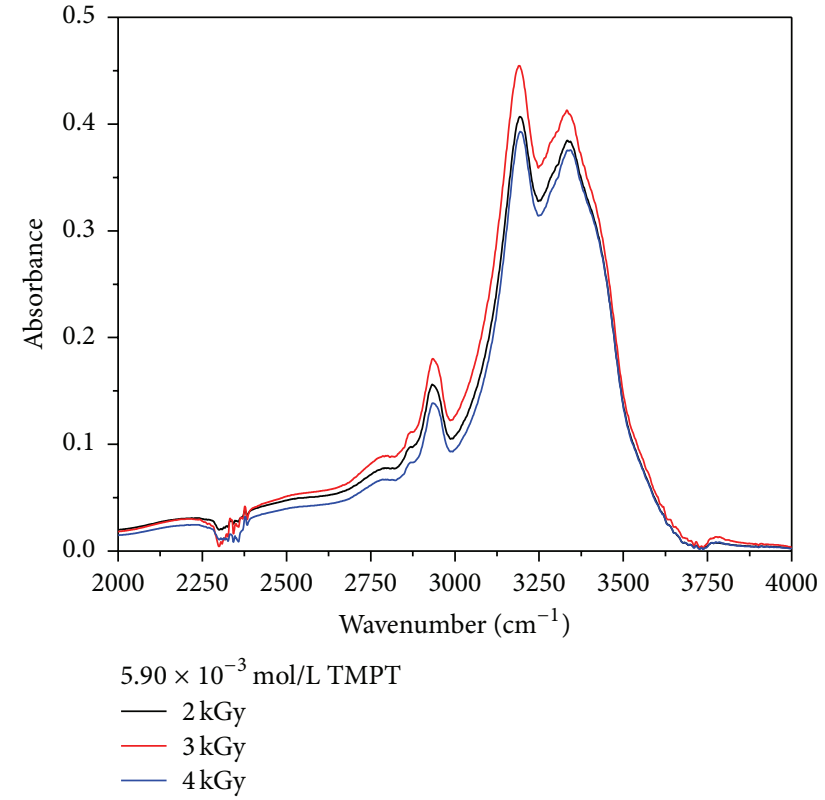

(b)

FIGURE 2: FTIR spectra for hydrogels having $5.90 \times 10^{-3} \mathrm{~mol} / \mathrm{L}$ TMPT, in the range of (a) $750-2000 \mathrm{~cm}^{-1}$ and (b) $2000-4000 \mathrm{~cm}^{-1}$.

the sample irradiated at the same dose, but with a lower content of TMPT $\left(2.95 \times 10^{-3} \mathrm{~mol} / \mathrm{L}\right)$, for which the swelling is almost $3500 \%$. Also, the swelling is strictly dependent on the absorbed dose. The swelling decreases with the increasing of absorbed dose, since the degree of cross-linking increases and the water entering is restricted.
3.3.3. Equilibrium Water Content. Another parameter used for the assessment of hydrogels swelling is the percentage of equilibrium water content (EWC\%) and it can be calculated from the following equation $[22,23]$ :

$$
\mathrm{EWC}=\frac{M_{S}-M_{0}}{M_{S}} \times 100
$$




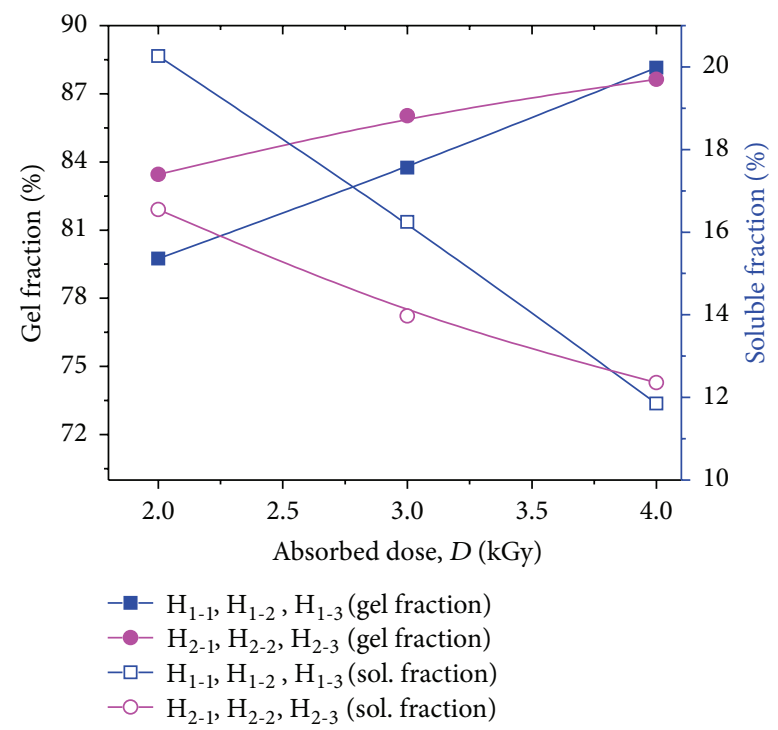

FIGURE 3: The effect of the absorbed dose and amount of PP and TMPT on gel fraction and soluble fraction of hydrogels.

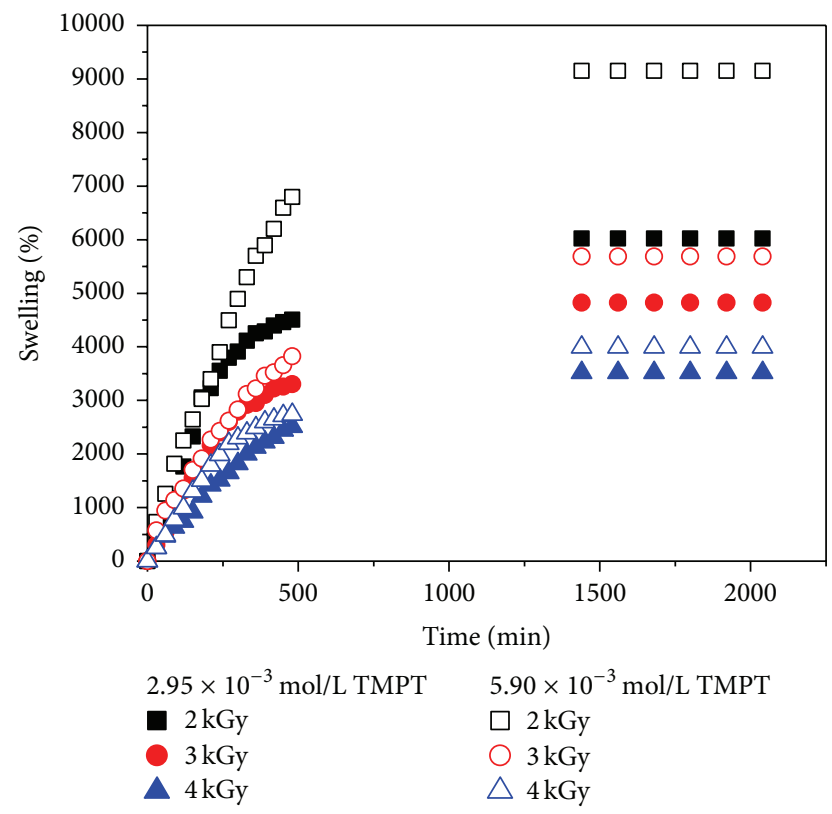

FIGURE 4: The effect of the absorbed dose and amount of TMPT on the hydrogels swelling.

where $M_{S}$ is the mass of the swollen gel at equilibrium and $M_{0}$ is the mass of the dried gel at time $t=0$.

The results are presented in Figure 5 and it can be noticed that all samples show values of EWC\% over 95\%, even for high irradiation doses. Also, the EWC\% values of hydrogels which contain high amounts of TMPT are larger compared to those that contain small amounts at the same absorbed dose. This result can be explained by the fact that TMPT is a hexafunctional cross-linker and its use in large amounts may form several bonds between chains [22].

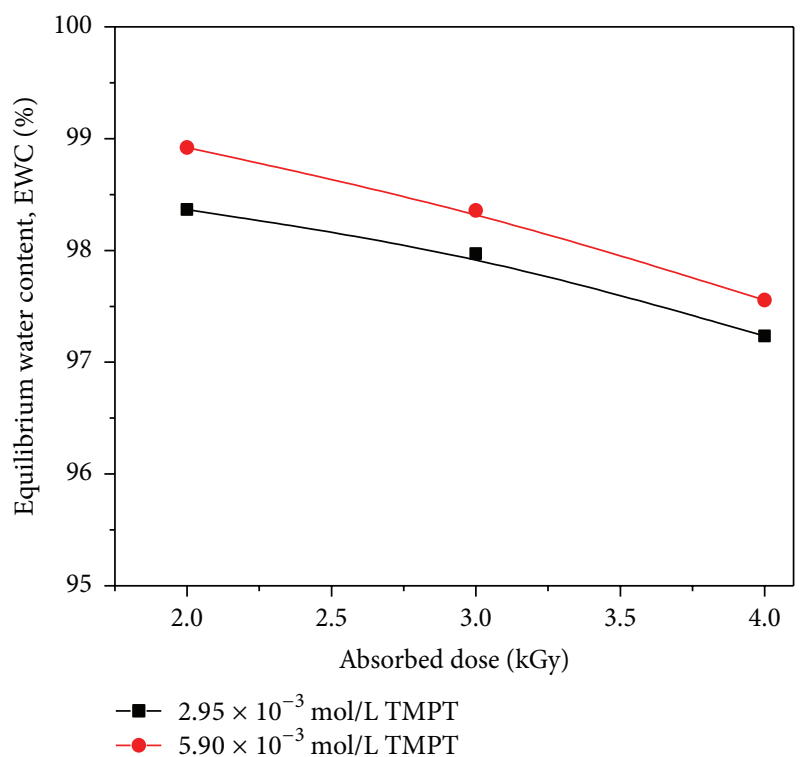

FIGURE 5: The effect of the absorbed dose and amount of TMPT on the equilibrium water content of hydrogels.

3.3.4. Swelling Kinetics. In order to examine the controlling mechanism of the swelling processes, several kinetic models are used to test experimental data. A simple kinetic analysis is the first-order equation in the form [15]

$$
\frac{d S}{d t}=k_{1, S}\left(S_{\text {max. }}-S\right)
$$

where $k_{1, S}$ is the rate constant of first-order swelling and $S_{\max }$. is the degree of swelling at equilibrium.

After the definite integration by applying the initial condition $(S=0$ at $t=0$ and $S=S$ at $t=t)$ equation becomes

$$
\begin{aligned}
\ln W & =k_{1, S} t, \\
W & =\frac{S_{\text {max. }}}{S_{\text {max. }}-S} .
\end{aligned}
$$

A second-order equation based on swelling equilibrium degree is expressed in the form [15]

$$
\frac{d S}{d t}=k_{2, S}\left(S_{\text {max. }}-S\right)^{2},
$$

where $k_{2, S}$ is the rate constant of second-order swelling.

After integration and applying the initial condition $(S=0$ at $t=0$ and $S=S$ at $t=t$ ), equation becomes

$$
\frac{t}{S}=A+B t
$$

where $A$ is the reciprocal of the initial swelling rate and $B$ is the inverse of the degree swelling at equilibrium:

$$
\begin{aligned}
& A=r_{0}=\frac{1}{k_{2, S} \times S_{\text {max. }}^{2}}, \\
& B=\frac{1}{S_{\text {max. }} .}
\end{aligned}
$$




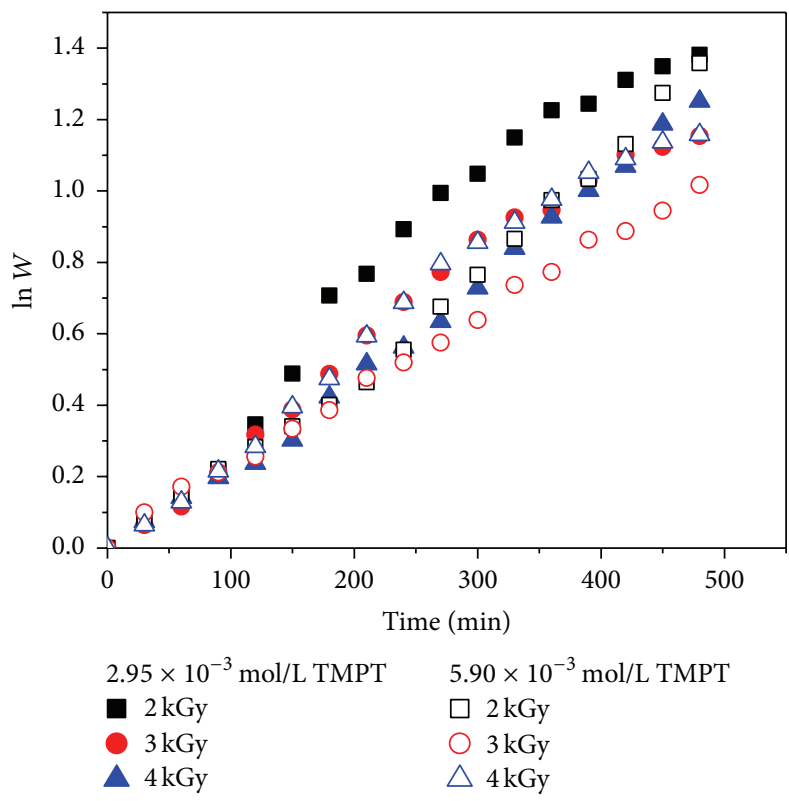

(a)

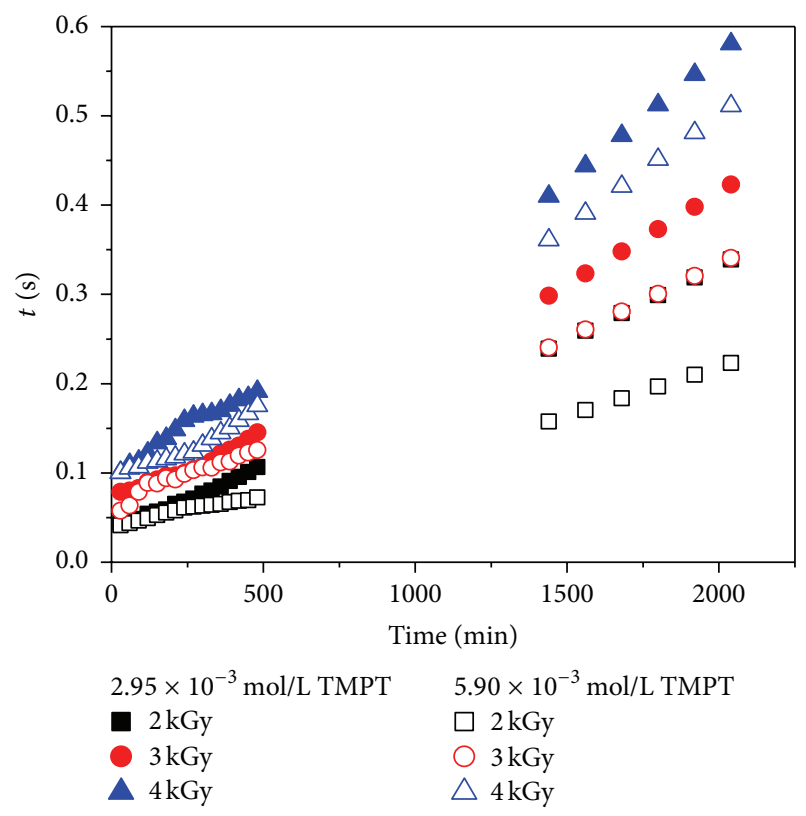

(b)

FIGURE 6: The first-order (a) and the second-order (b) swelling kinetics of hydrogels.

TABLE 3: The variation of first-order $k_{1, S} / \mathrm{min}^{-1}$ and second-order $k_{2, S}$ /g gel (g water min) $)^{-1}$ swelling rate constants with the amount of TMPT and absorbed dose.

\begin{tabular}{lccc}
\hline TMPT (mol/L) & \multicolumn{3}{c}{ Absorbed dose (kGy) } \\
& 2 & 3 & 4 \\
\hline \multirow{3}{*}{$k_{1, S} \times 10^{3}$} \\
$2.95 \times 10^{-3}$ & 3.14 & 2.59 & 2.65 \\
$5.90 \times 10^{-3}$ & 2.81 & 2.08 & 2.61 \\
\hline & \multicolumn{3}{c}{$k_{2, S} \times 10^{7}$} \\
$2.95 \times 10^{-3}$ & 6.28 & 4.65 & 5.83 \\
$5.90 \times 10^{-3}$ & 2.15 & 2.65 & 5.46 \\
\hline
\end{tabular}

Also, by fitting the experimental data using the firstorder equation and the second-order equation (Figure 6), the swelling kinetic parameters including the rate constant of first- and second-order swelling $\left(k_{1, S}\right.$ and $\left.k_{2, S}\right)$, the theoretical degree swelling at equilibrium $\left(S_{\text {max. }}\right)$, and the initial swelling rate $\left(r_{0}\right)$ can be calculated from the slope and intercept of lines (Figure 6). The results are listed in Tables 3 and 4.

From Table 3 it is observed that the swelling rate constant decreases with the increase in the amount of TMPT, indicating that the diffusion rate decreases at higher TMPT concentrations. This suggests that the water diffusion at higher TMPT concentrations is hindered due to steric obstacles caused by association which leads to denser gel structure [24].

It can be noticed that the initial swelling rate constant $\left(r_{0}\right)$ of the hydrogels has rapidly increased with the increasing of absorbed dose for both TMPT concentrations. For samples which contain a higher amount of cross-linker, the initial swelling rate constant is small at the highest absorbed dose,
TABLE 4: The variation of initial swelling rate $r_{0} / \mathrm{g}$ water $\left(\mathrm{g}\right.$ gel $\left.\mathrm{min}^{-1}\right)$ and equilibrium swelling degrees (theoretical) $S_{\max } / \mathrm{g}$ water $(\mathrm{g} \text { gel })^{-1}$ with the amount of TMPT and absorbed dose.

\begin{tabular}{lccc}
\hline \multirow{2}{*}{ TMPT (mol/L) } & \multicolumn{3}{c}{ Absorbed dose (kGy) } \\
& 2 & 3 & 4 \\
\hline $2.95 \times 10^{-3}$ & 3.42 & 6.29 & 9.21 \\
$5.90 \times 10^{-3}$ & 3.63 & 6.44 & 7.76 \\
\hline & & $r_{\text {max. }} \times 10^{2}$ & \\
$2.95 \times 10^{-3}$ & 6820 & 5843 & 4315 \\
$5.90 \times 10^{-3}$ & 11321 & 7651 & 4859 \\
\hline
\end{tabular}

compared with the samples that have a lower content of crosslinker at the same absorbed dose ( $4 \mathrm{kGy}$ ). TMPT has a high degree of functionality, fast undergoes addition reactions, and increases the cross-linking degree of the hydrogels. The swelling properties of hydrogels containing cross-linkers are changed because of the structure of cross-linker. When the cross-linkers are added to the hydrogel systems, it is known that they will cause changes in the swelling ratio of hydrogels, because the molecules of cross-linkers are placed between the chains of monomers [25]. The maximum equilibrium swelling ratios theoretically calculated are in a good agreement with the equilibrium swelling ratios experimentally obtained. As it is shown in Figure 6, the second-order swelling equation seems to fit better than the first-order equation.

3.3.5. Determination of Swelling Power. Because of the hydrogels applications in biomedicine, pharmaceutical, environmental, and agricultural engineering, the analysis of the 
mechanisms of water diffusion has gained considerable attention lately. When a glassy hydrogel is brought in contact with water, water diffuses into the hydrogel and the hydrogel swells. Diffusion involves migration of water into preexisting or dynamically formed spaces between the chains of hydrogel. The swelling of hydrogels involves a larger scale segmental motion, resulting ultimately in an increased distance of separation between hydrogel chains. By the exploiting of the swelling experiment, the diffusion of water into hydrogel can be determined. By applying the following equation to the $60 \%$ of swelling curves, the nature of the diffusion of water into hydrogels can be evaluated [25]:

$$
\begin{aligned}
F_{\text {swp }} & =\frac{M_{t}-M_{0}}{M_{0}}=k t^{n}, \\
\ln F_{\text {swp }} & =n \ln t+\ln k,
\end{aligned}
$$

where $M_{t}$ and $M_{0}$ are the mass of the swollen and dry sample at time $t, k$ is the swelling constant, and $n$ is the swelling exponent which is indicative of the transport mechanism.

The abovementioned equation is valid for the first $60 \%$ from the fractional uptake. For the hydrogels obtained in this study, $\ln F$ versus $\ln t$ values are plotted and are shown in Figure 7. The swelling constant and swelling exponent are calculated from the slopes and intercepts of the lines, respectively, and are listed in Table 5. According to the relative rates of diffusion $\left(R_{\text {diff }}\right)$ and relaxation $\left(R_{\text {relax }}\right)$, there are three cases of diffusion [26-28]: Case I: $n=0.45-0.5$ indicates a Fickian diffusion mechanism, in which the rate of diffusion is much smaller than the rate of relaxation $\left(R_{\text {diff }} \ll R_{\text {relax }}\right)$ and the system is controlled by diffusion; Case II: $n=1.0$, where the diffusion process is much faster than the relaxation process $\left(R_{\text {diff }} \gg R_{\text {relax }}\right)$ and the system is controlled by relaxation; Case III: $0.5<n<1.0$ indicates non-Fickian (anomalous) diffusion mechanism, which describes those cases where the diffusion and relaxation rates are comparable $\left(R_{\text {diff }} \approx R_{\text {relax }}\right)$. Occasionally, when $n>1$, the situation is regarded as Super Case II kinetics [26, 29, 30].

From Table 5 it is observed that the values of swelling coefficient vary between 0.7 and 0.89 . Due to these results, we can say that the diffusion of water into the hydrogels obtained in this study shows a non-Fickian character.

The study of water diffusion phenomena in hydrogels clarifies the polymer behavior. The swelling-time curves of hydrogels in water are used to calculate the diffusion coefficients. One of the methods for calculating the diffusion coefficient $(D)$ is the short time approximation method. This method is valid only for the first $60 \%$ of the swelling [15]. The diffusion coefficients have been calculated using the following relation:

$$
F=4\left[\frac{D}{\pi \times r^{2}}\right]^{1 / 2} t^{1 / 2}
$$

where $D$ is in $\mathrm{cm}^{2} \mathrm{sec}^{-1}, t$ is in sec, and $r$ is the radius of cylindrical polymer sample $(\mathrm{cm})$.

For the hydrogels obtained in this study, the graphs of $F$ versus $t^{1 / 2}$ are showed in Figure 8. The diffusion coefficients
TABLE 5: The variation of $n$ and $k$ with the amount of TMPT and absorbed dose.

\begin{tabular}{lccc}
\hline TMPT (mol/L) & \multicolumn{3}{c}{ Absorbed dose (kGy) } \\
& 2 & 3 & 4 \\
\hline \multirow{3}{*}{$\begin{array}{c}n \\
2.95 \times 10^{-3}\end{array}$} & 0.86 & 0.89 & 0.85 \\
$5.90 \times 10^{-3}$ & 0.82 & 0.70 & 0.88 \\
\hline & & $k$ & \\
$2.95 \times 10^{-3}$ & 0.281 & 0.164 & 0.137 \\
$5.90 \times 10^{-3}$ & 0.444 & 0.507 & 0.142 \\
\hline
\end{tabular}

TABLE 6: The variation of the diffusional coefficient $(D \times$ $10^{-4} / \mathrm{cm}^{2} \mathrm{sec}^{-1}$ ) with the amount of TMPT and absorbed dose.

\begin{tabular}{lccc}
\hline \multirow{2}{*}{ TMPT $(\mathrm{mol} / \mathrm{L})$} & \multicolumn{3}{c}{ Absorbed dose $(\mathrm{kGy})$} \\
& 2 & 3 & 4 \\
\hline $2.95 \times 10^{-3}$ & 2.43 & 2.15 & 1.63 \\
$5.90 \times 10^{-3}$ & 16.17 & 5.49 & 4.08 \\
\hline
\end{tabular}

were calculated from the slopes of the lines and the results are listed in Table 6.

From Table 6 the increasing trend for diffusional coefficients with the increase of TMPT amount and their decreasing trend with the decrease of absorbed dose are observed. From Figure 5 it is observed that the equilibrium water content shows the same variation trend. This can be explained as follows: the increasing of the number of cross-links inside the network per volume unit leads to the decreasing of the free spaces for water molecules, so the water uptake decreases.

3.3.6. Network Studies. One of the most important structural parameters for the characterization of the cross-linked polymers is $M_{c}$, the average molar mass between cross-links, which is directly related to the cross-link density. The swelling equilibrium is widely used to determine $M_{c}$. According to the theory of Flory and Rehner for a perfect network, $M_{c}$ is calculated using the following relation [15]:

$$
M_{c}=-V_{1} d_{p} \frac{v_{S}^{1 / 3}-\nu_{S} / 2}{\ln \left(1-\nu_{S}\right)+\nu_{S}+\chi v_{S}^{2}},
$$

where $V_{1}$ is the molar volume of the solvent (in this case water: $\left.18 \mathrm{~cm}^{3} \mathrm{~mol}^{-1}\right), d_{p}$ is the polymer density $\left(1.106 \mathrm{~g} \mathrm{~cm}^{-3}\right), v_{S}$ is the volume fraction of the polymer in the swollen gel $\left(\mathrm{cm}^{3}\right)$ and is equal to $1 / S$, and $\chi$ is the Flory-Huggins interaction parameter between the solvent and polymer.

The value of $\chi$ is calculated as follows [31-33]:

$$
\chi=0.431-0.311 \nu_{S}-0.036 v_{S}^{2}
$$

The cross-link density, $q$, is defined as being the mole fraction of the cross-linked units:

$$
q=\frac{M_{0}}{M_{c}}
$$




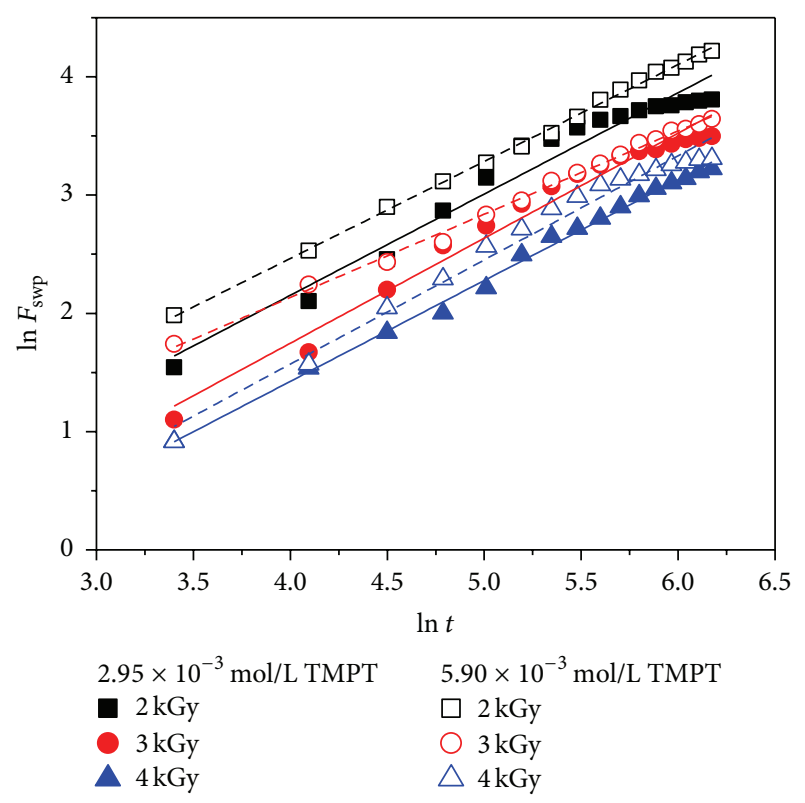

FIgURE 7: The plots of $\ln F$ versus $\ln t$ for hydrogels.

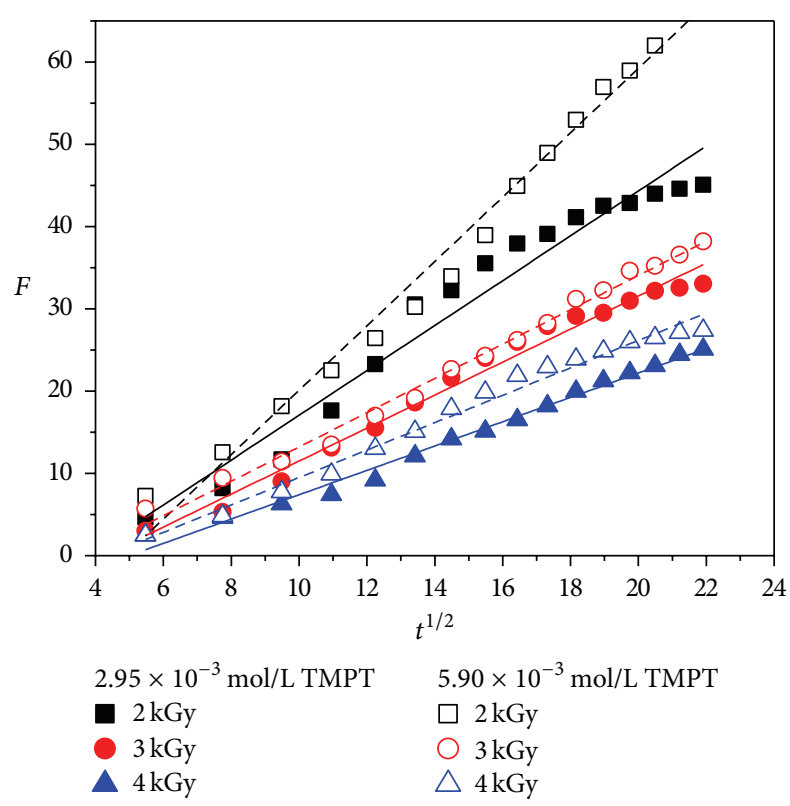

Figure 8: Plots of $F$ versus $t^{1 / 2}$ for hydrogels.

where $M_{0}$ is the molecular weight of the repeating units from polymer and is calculated using the following relation $[31,33]$ :

$$
\begin{aligned}
& M_{0} \\
& =\frac{\left(m_{\mathrm{AMD}} \times M_{\mathrm{AMD}}\right)+\left(m_{\mathrm{AA}} \times M_{\mathrm{AA}}\right)+\left(m_{\mathrm{TMPT}} \times M_{\mathrm{TMPT}}\right)}{m_{\mathrm{AMD}}+m_{\mathrm{AA}}+m_{\mathrm{TMPT}}},
\end{aligned}
$$

where $m_{\mathrm{AMD}}, m_{\mathrm{AA}}$, and $m_{\mathrm{TMPT}}$ are the masses of acrylamide, acrylic acid, and cross-linker (TMPT) expressed in grams and $M_{\mathrm{AMD}}, M_{\mathrm{AA}}$, and $M_{\mathrm{TMPT}}$ are the molar masses of acrylamide, acrylic acid, and TMPT expressed in $\mathrm{g} \mathrm{mol}^{-1}$.
TABLE 7: The variation of the number-average molar mass between cross-links $\left(M_{c} / \mathrm{g} \mathrm{mol}^{-1}\right)$, cross-link density $(q)$, and number of elastically effective chains $\left(v_{e}\right)$ with the amount of TMPT and absorbed dose.

\begin{tabular}{lccc}
\hline \multirow{2}{*}{ TMPT (mol/L) } & \multicolumn{3}{c}{ Absorbed dose (kGy) } \\
& 2 & 3 & 4 \\
$2.95 \times 10^{-3}$ & 589817 & 407327 & 239736 \\
$5.90 \times 10^{-3}$ & 1187695 & 584394 & 296537 \\
\hline & & $q \times 10^{-3}$ & \\
$2.95 \times 10^{-3}$ & 1.218 & 1.764 & 2.997 \\
$5.90 \times 10^{-3}$ & 0.610 & 1.241 & 2.445 \\
\hline & & $v_{e} \times 10^{14}$ & \\
$2.95 \times 10^{-3}$ & 1.875 & 2.715 & 4.613 \\
$5.90 \times 10^{-3}$ & 0.931 & 1.892 & 3.729 \\
\hline
\end{tabular}

Another parameter used for cross-link density characterization is $v_{e}$ which represents the number of elastically effective chains totally included in a network per volume unit and it is calculated with the following relation:

$$
v_{e}=\frac{d_{p} N_{A} q}{M_{0}},
$$

where $N_{A}$ is the Avogadro number.

The values of parameters $M_{c}, q$, and $v_{e}$ were calculated as above and are listed in Table 7.

From Table 7 it is observed that the number-average molar mass between cross-links of hydrogels has increased with the increasing of the amount of cross-linker (TMPT) but has decreased with the increasing of absorbed dose. The values of the cross-link density and number of elastically effective chains are inversed due to the value of numberaverage molar mass between cross-links. The increasing of the amount of cross-linker decreases the cross-linking density and increases the swelling (Figure 5), because the hydrogels obtained are not stiff. Increasing the cross-linker concentration increases $M_{c}$ between the two main backbones. A large value of $M_{c}$ indicates long chains between the two backbones. The obtained results show that the $M_{c}$ values are affected by the absorbed dose. The increasing of absorbed dose leads to the decreasing of $M_{c}$, since the hydrogel becomes more and more dense. However, AMD includes several hydrophilic fragments and thus the hydrogels show a high degree of swelling.

Other important parameters used for the assessment of networks are gel pore size or mesh size $(\xi)$ and porosity $(P \%)$. Using the calculated values of number-average molecular mass between cross-links, $M_{c}$, the mesh size was determined with the following equation [34]:

$$
\xi=v_{S}^{-1 / 3} \sqrt{\frac{2 C_{n} M_{c}}{M_{r}}}
$$

where $v_{S}$ is the volume fraction of the polymer in the swollen gel, $l$ is the length of the $\mathrm{C}-\mathrm{C}$ bond along the polymer backbone $(0.154 \mathrm{~nm}), C_{n}$ is the Flory characteristic ratio of 


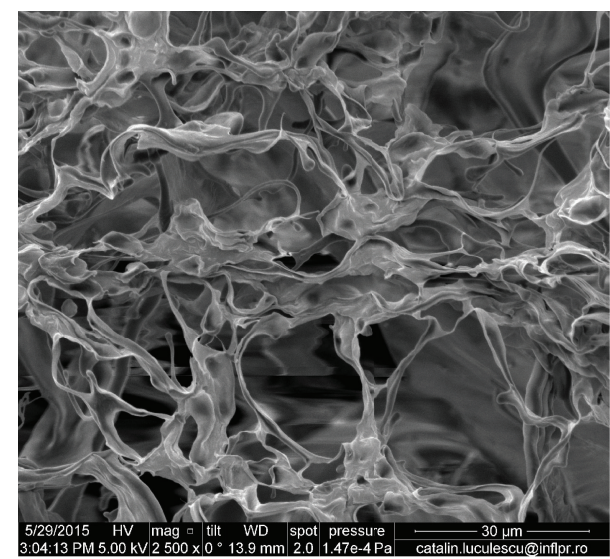

(a)

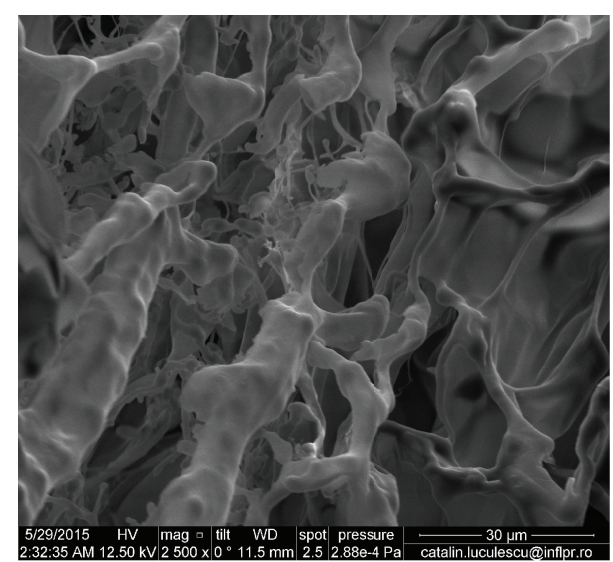

(b)

FIGURE 9: Scanning electron micrographs of hydrogels obtained by electron beam irradiation at $2 \mathrm{kGy}$ : (a) $2.95 \times 10^{-3} \mathrm{~mol} / \mathrm{L}$ TMPT; (b) 5.90 $\times 10^{-3} \mathrm{~mol} / \mathrm{L}$ TMPT.

TABLE 8: The variation of mesh size $(\xi)$ and porosity $(P)$ with the amount of TMPT and absorbed dose.

\begin{tabular}{lccc}
\hline \multirow{2}{*}{ TMPT (mol/L) } & \multicolumn{3}{c}{ Absorbed dose (kGy) } \\
& 2 & 3 & 4 \\
\hline \multirow{3}{*}{$2.95 \times 10^{-3}$} & 161.46 & 124.81 & 86.37 \\
$5.90 \times 10^{-3}$ & 262.94 & 160.43 & 100.11 \\
\hline & & $P(\%)$ & \\
$2.95 \times 10^{-3}$ & 98.34 & 97.93 & 97.15 \\
$5.90 \times 10^{-3}$ & 98.91 & 98.33 & 97.49 \\
\hline
\end{tabular}

the polymer, and $M_{r}$ is the molecular mass of the repeated unit.

The characteristic ratio $C_{n}$, for poly(AMD-co-AA) hydrogels, was taken as the weighted average of $C_{n}$ values for poly(AMD) and poly(AA) chains, according to their molar ratio in the hydrogel $\left(C_{n}\right.$ was taken as 8.8 and 6.7 for poly(AMD) and poly(AA), resp.).

The porosity $P(\%)$ of the obtained hydrogels was determined using the following equation [15]:

$$
P(\%)=\frac{V_{d}}{1-V_{d}} \times 100
$$

where $V_{d}$ is the volume ratio of water at equilibrium. The values of the mesh size $\xi(\mathrm{nm})$ and porosity $(P)$ are shown in Table 8.

As it is presented in Table 8, the mesh size and porosity have increased with the increasing of the amount of crosslinker (TMPT) and have decreased with increasing of the absorbed dose. The mesh size is related to the space available for transport of a solute or of a solvent in a network. The increasing of the mesh size and porosity results in the increasing of water content in the hydrogel. More than that, from the results it is observed that the degree of cross-linking had a significant influence on the mesh size. Hydrogels having higher degree of cross-linking have a relatively shorter distance between two cross-linking points and as a result, the mesh sizes and porosity of these hydrogels are lower.

3.4. SEM Analysis. The surface appearance and the structure of copolymers were observed using the technique of Scanning Electron Microscopy. The scanning electron micrographs of hydrogels obtained by electron beam irradiation at $2 \mathrm{kGy}$, $3 \mathrm{kGy}$, and $4 \mathrm{kGy}$, respectively, are shown in Figures 9-11.

The cross-link density and composition affect the microstructure of hydrogels which in turn influences the swelling characteristics. From the results presented in Table 7 it is observed that the cross-link density of hydrogels has decreased with the increasing of the amount of cross-linker (TMPT) but has increased with the increasing of absorbed dose. On the other hand, the mesh size and porosity have increased with the increasing of the amount of cross-linker (TMPT) and have decreased with increasing of the absorbed dose (Table 8). As it can be seen from Figures 9(a) and 9(b), the hydrogels having a high amount of TMPT $(5.90 \times$ $10^{-3} \mathrm{~mol} / \mathrm{L}$ ) and irradiated at $2 \mathrm{kGy}$ have presented a more open and porous channel structure than the hydrogels having a lower content of TMPT $\left(2.95 \times 10^{-3} \mathrm{~mol} / \mathrm{L}\right)$ and irradiated at the same irradiation dose. These pores facilitate the transport of water [35-37]. The results are in concordance with the observations from swelling studies. With the increasing of the absorbed dose, the morphology of the hydrogels is changing. The SEM micrographs of the hydrogels obtained at $3 \mathrm{kGy}$ (Figure 10) show a semiporous structure with thick struts between pores (a) and a porous structure with a broad network (b). As it can be seen from Figures 11(a) and 11(b), the SEM micrographs of hydrogels obtained at $4 \mathrm{kGy}$ present an irregular surface with semiporous structure, with macroand micropores within the hydrogels.

\section{Conclusions}

In this paper the synthesis and characterization of some hydrogels prepared by free-radical copolymerization of acrylamide and acrylic acid in aqueous solutions using potassium 


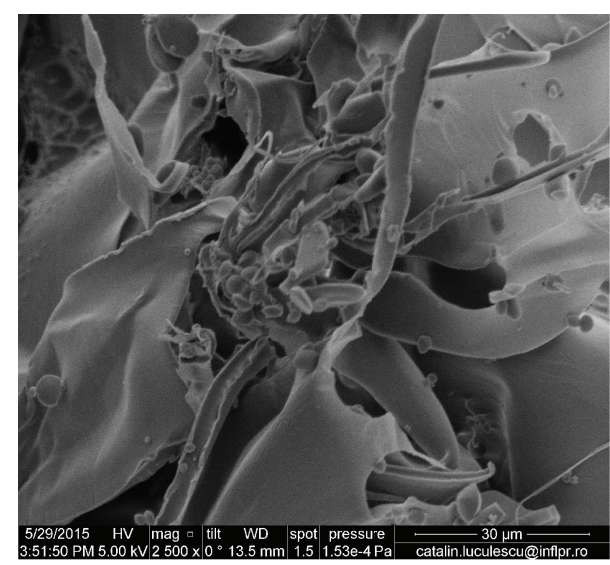

(a)

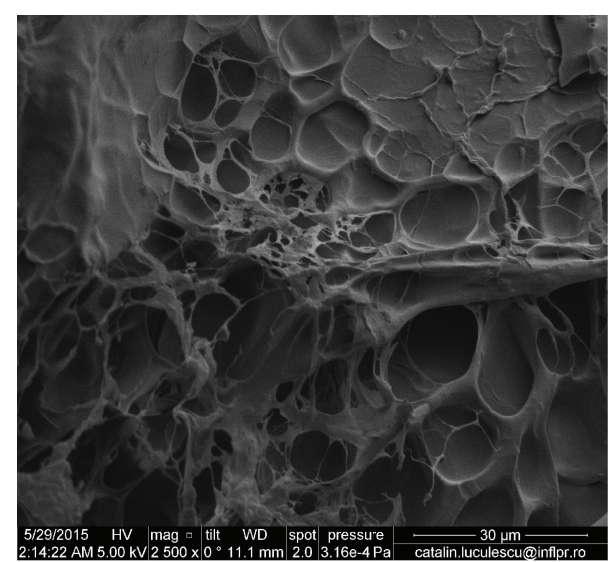

(b)

FIGURE 10: Scanning electron micrographs of hydrogels obtained by electron beam irradiation at $3 \mathrm{kGy}$ : (a) $2.95 \times 10^{-3} \mathrm{~mol} / \mathrm{L}$ TMPT; (b) 5.90 $\times 10^{-3} \mathrm{~mol} / \mathrm{L}$ TMPT.

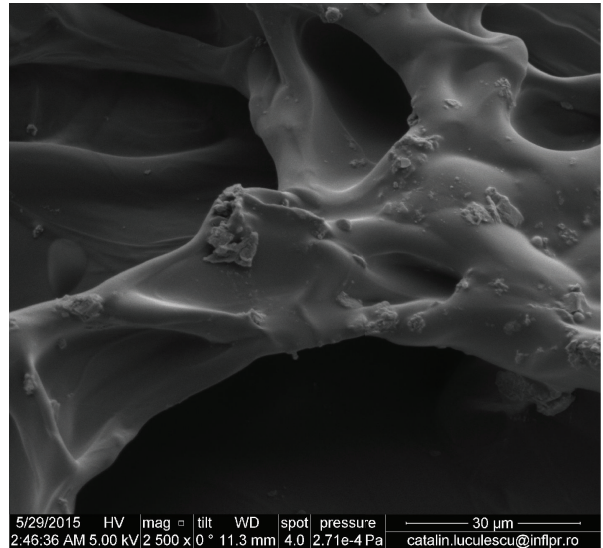

(a)

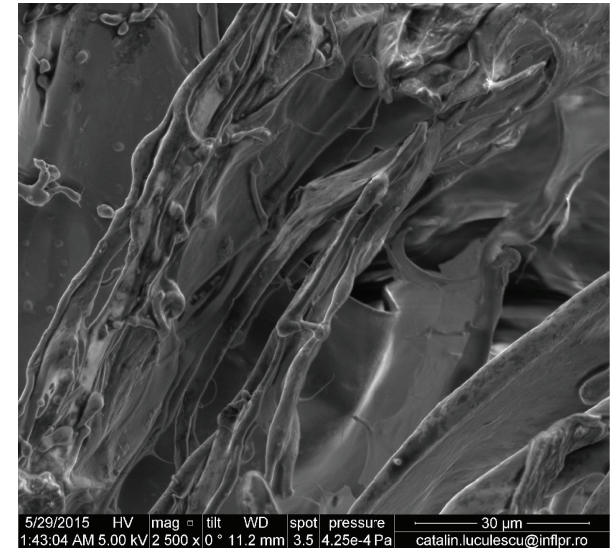

(b)

FIGURE 11: Scanning electron micrographs of hydrogels obtained by electron beam irradiation at $4 \mathrm{kGy}$ : (a) $2.95 \times 10^{-3} \mathrm{~mol} / \mathrm{L}$ TMPT; (b) 5.90 $\times 10^{-3} \mathrm{~mol} / \mathrm{L}$ TMPT.

persulfate as initiator and trimethylolpropane trimethacrylate as cross-linker are presented. The hydrogels were obtained by electron beam irradiation in the dose range of 2 to $4 \mathrm{kGy}$ in atmospheric conditions and at room temperature. The cross-linker was used in conjunction with the radical cure systems in order to improve physical properties of the final product. A possible reaction mechanism was proposed. Therefore, the reaction in presence of TMPT was described as a two-step process: the first step consists of the rapid initial polymerization of the polyfunctional monomer and in the second step the reaction between the polymerized polyfunctional monomer and the chains of AMD/AA takes place in order to form a cross-linked AMD/AA-TMPT network. The infrared spectroscopy was carried out in order to investigate the chemical structure of the obtained hydrogels. So, the symmetric and asymmetric - NH stretching vibrations of AMD and the absorptions of $-\mathrm{OH}$ groups of AA were highlighted. For monitoring the extension of polymerization, the methylene group vibrations were used. The asymmetrical stretching vibrations of $-\mathrm{CH}_{2}$ from AMD or AA were highlighted also. Were also found the bands which correspond to the carbonyl stretching vibration of $\mathrm{C}=\mathrm{O}$ connected to the carboxyl group and amide group. From polyacrylamide, the $-\mathrm{CN}$ stretching and $-\mathrm{C}-\mathrm{O}$ stretching have been found. The $\mathrm{C}-\mathrm{O}-\mathrm{C}$ asymmetric stretching and $\mathrm{C}-\mathrm{O}$ stretching from $\mathrm{AA}$ were confirmed.

The obtained hydrogels were investigated through swelling and diffusion experiments. Thus, gel fraction and swelling measurements, evaluations of the equilibrium water content and kinetics of swelling, determination of swelling power, and finally network studies were performed. It was found that the gel fraction depends on the concentration of TMPT, increases with the radiation dose increasing, and attains a maximum at the radiation dose of $4 \mathrm{kGy}$. The swelling is strictly dependent on the absorbed dose. It presents an increasing with the increasing of the amount of TMPT at the same absorbed dose and a decreasing with the increasing of absorbed dose, since the degree of cross-linking 
is increased and the water entering is restricted. Swelling of the hydrogels having $2.95 \times 10^{-3} \mathrm{~mol} / \mathrm{L}$ cross-linker has increased up to $2000 \%$, while swelling of the hydrogels having $5.9 \times 10^{-3} \mathrm{~mol} / \mathrm{L}$ cross-linker has increased up to $3000 \%$. The percentage of the equilibrium water content for the hydrogels which contain a high amount of TMPT was found higher compared to those which contain smaller amounts obtained at the same absorbed dose. The maximum equilibrium swelling ratios theoretically calculated are in a good agreement with the equilibrium swelling ratios experimentally obtained.

Diffusion coefficients of hydrogels were calculated by the short time approximation and were found as being $1.43 \times 10^{-4}-1.64 \times 10^{-4} / \mathrm{cm}^{2} \mathrm{sec}^{-1}$ and $16.17 \times 10^{-4}-3.21 \times$ $10^{-4} / \mathrm{cm}^{2} \mathrm{sec}^{-1}$ for a cross-linker concentration of $2.95 \times$ $10^{-3} \mathrm{~mol} / \mathrm{L}$ and of $5.9 \times 10^{-3} \mathrm{~mol} / \mathrm{L}$, respectively. They have the same variation trend as the equilibrium water content. They increase with the increasing of TMPT amount and decrease with the decreasing of absorbed dose. The number-average molar mass between cross-links of hydrogels increased with the increasing of the amount of cross-linker (TMPT) but decreased with the increasing of absorbed dose. Also, the mesh size and porosity have increased with the increasing of the amount of cross-linker (TMPT) and have decreased with increasing of the absorbed dose. Hydrogels having higher degree of cross-linking have a relatively shorter distance between two cross-linking points and for this reason, the mesh sizes and porosity of these hydrogels have decreased.

The surface appearance and the structure of copolymers were observed also using the technique of Scanning Electron Microscopy. The hydrogels having a high amount of TMPT $\left(5.90 \times 10^{-3} \mathrm{~mol} / \mathrm{L}\right)$ and irradiated at $2 \mathrm{kGy}$ have presented a more open and porous channel structure than the hydrogels having a lower content of TMPT $\left(2.95 \times 10^{-3} \mathrm{~mol} / \mathrm{L}\right)$ and irradiated at the same irradiation dose. The results are in concordance with the observations from swelling studies. With the increasing of the absorbed dose, the morphology of the hydrogels is changing. The SEM micrographs of the hydrogels obtained at $3 \mathrm{kGy}$ show a semiporous structure with thick struts between pores and a porous structure with a broad network. The SEM micrographs of hydrogels obtained at $4 \mathrm{kGy}$ present an irregular surface with semiporous structure.

\section{Competing Interests}

The authors declare that they have no competing interests.

\section{Acknowledgments}

The authors thank Dr. Catalin Luculescu for his support given to the achieving of the samples investigation by SEM technique. The researches were financed by the Romanian Program "LAPLAS IV” no. 4N/3.03.2016.

\section{References}

[1] E. Karadag, D. Saraydin, Y. Caldiran, and O. Guven, "Swelling studies of copolymeric acrylamide/crotonic acid hydrogels as carriers for agricultural uses," Polymers for Advanced Technologies, vol. 11, pp. 59-68, 2000.

[2] G. R. Bardajee, A. Pourjavadi, N. Sheikh, and M. S. AminiFazl, "Grafting of acrylamide onto kappa-carrageenan via $\gamma$ irradiation: optimization and swelling behavior," Radiation Physics and Chemistry, vol. 77, no. 2, pp. 131-137, 2008.

[3] D. SaraydIn, E. Karadag, and O. Güven, "Relationship between the swelling process and the releases of water soluble agrochemicals from radiation crosslinked acrylamide/itaconic acid copolymers," Polymer Bulletin, vol. 45, no. 3, pp. 287-294, 2000.

[4] G. B. Marandi, G. R. Mahdavinia, and S. Ghafary, "Collageng-poly(Sodium Acrylate-co-Acrylamide)/sodium montmorillonite superabsorbent nanocomposites: synthesis and swelling behavior," Journal of Polymer Research, vol. 18, no. 6, pp. 14871499, 2011.

[5] S. K. H. Gulrez, S. Al-Assaf, and G. O. Phillips, "Hydrogels: methods of preparation, characterisation and applications," in Progress in Molecular and Environmental Bioengineering-From Analysis and Modeling to Technology Applications, A. Carpi, Ed., pp. 117-150, InTech, Rijeka, Croatia, 2011.

[6] W. E. Hennink and C. F. Van Nostrum, "Novel crosslinking methods to design hydrogels," Advanced Drug Delivery Reviews, vol. 54, no. 1, pp. 13-36, 2002.

[7] J. M. Rosiak and F. Yoshii, "Hydrogels and their medical applications," Nuclear Instruments and Methods in Physics Research, Section B: Beam Interactions with Materials and Atoms, vol. 151, no. 1-4, pp. 56-64, 1999.

[8] H. M. Said, S. G. Abd Alla, and A. W. M. El-Naggar, "Synthesis and characterization of novel gels based on carboxymethyl cellulose/acrylic acid prepared by electron beam irradiation," Reactive and Functional Polymers, vol. 61, no. 3, pp. 397-404, 2004.

[9] B. Fei, R. A. Wach, H. Mitomo, F. Yoshii, and T. Kume, "Hydrogel of biodegradable cellulose derivatives. I. Radiationinduced crosslinking of CMC," Journal of Applied Polymer Science, vol. 78, no. 2, pp. 278-283, 2000.

[10] P. Liu, M. Zhai, J. Li, J. Peng, and J. Wu, "Radiation preparation and swelling behavior of sodium carboxymethyl cellulose hydrogels," Radiation Physics and Chemistry, vol. 63, no. 3-6, pp. 525-528, 2002.

[11] E. Karadağ, D. Saraydin, and O. Güven, "Water absorbency studies of $\gamma$-radiation crosslinked poly(acrylamide-co-2,3-dihydroxybutanedioic acid) hydrogels," Nuclear Instruments and Methods in Physics Research Section B: Beam Interactions with Materials and Atoms, vol. 225, no. 4, pp. 489-496, 2004.

[12] M. Fiti, Dozimetria Chimica a Radiatiilor Ionizante, Editura Academiei Republicii Socialiste Romania, Bucuresti, Romania, 1973.

[13] M. Fiti, Actiunea Radiatiilor Ionizante Asupra Apei Si Solutiilor Apoase, Editura Academiei Republicii Socialiste Romania, Bucharest, Romania, 1967.

[14] N. W. Holm and Z. P. Zagorski, "Aqueous chemical dosimetry," in Manual on Radiation Dosimetry, pp. 85-88, Marcel Dekker, New York, NY, USA, 1970.

[15] E. Karadag, D. Saraydin, N. Sahiner, and O. Güven, "Radiation induced acrylamide/citric acid hydrogels and their swelling behaviors," Journal of Macromolecular Science-Part A: Pure and Applied Chemistry, vol. 38, no. 11, pp. 1105-1121, 2001.

[16] M. D. Stelescu, E. Manaila, and G. Craciun, "Vulcanization of ethylene-propylene-terpolymer-based rubber mixtures by radiation processing," Journal of Applied Polymer Science, vol. 128, no. 4, pp. 2325-2336, 2013. 
[17] M. D. Stelescu, E. Manaila, and N. Zuga, "The use of polyfunctional monomers in the radical cure of chlorinated polyethylene," Polymer Journal, vol. 43, no. 9, pp. 792-800, 2011.

[18] S. Nesrinne and A. Djamel, "Synthesis, characterization and rheological behavior of $\mathrm{pH}$ sensitive poly(acrylamide-coacrylic acid) hydrogels," Arabian Journal of Chemistry, 2013.

[19] R. Murugan, S. Mohan, and A. Bigotto, "A bigotto, FTIR and polarised raman spectra of acrylamide and polyacrylamide," Journal of the Korean Physical Society, vol. 32, no. 4, pp. 505$512,1998$.

[20] R. Geethanjali, A. A. Sabirneeza, and S. Subhashini, "Watersoluble and biodegradable pectin-grafted polyacrylamide and pectin-grafted polyacrylic acid: electrochemical investigation of corrosion-inhibition behaviour on mild steel in $3.5 \% \mathrm{NaCl}$ Media," Indian Journal of Materials Science, vol. 2014, Article ID 356075, 9 pages, 2014.

[21] H. M. Nizam El-Din, S. G. Abd Alla, and A. W. M. ElNaggar, "Radiation synthesis and characterization of hydrogels composed of poly(vinyl alcohol) and acrylamide mixtures," Journal of Macromolecular Science, Part A: Pure and Applied Chemistry, vol. 44, no. 1, pp. 47-54, 2007.

[22] E. Karadağ and D. Saraydin, "Swelling studies of super water retainer acrylamide/crotonic acid hydrogels crosslinked by trimethylolpropane triacrylate and 1,4-butanediol dimethacrylate," Polymer Bulletin, vol. 48, no. 3, pp. 299-307, 2002.

[23] A. Pourjavadi and M. Kurdtabar, "Collagen-based highly porous hydrogel without any porogen: synthesis and characteristics," European Polymer Journal, vol. 43, no. 3, pp. 877-889, 2007.

[24] M. Davidovich-Pinhas and H. Bianco-Peled, "A quantitative analysis of alginate swelling," Carbohydrate Polymers, vol. 79, no. 4, pp. 1020-1027, 2010.

[25] E. Karadag, O. B. Uzum, and D. Saraydin, "Swelling equilibria and dye adsorption studies of chemically crosslinked superabsorbent acrylamide/maleic acid hydrogels," European Polymer Journal, vol. 38, no. 11, pp. 2133-2141, 2002.

[26] M. Gierszewska-Druzyńska and J. Ostrowska-Czubenko, "Mechanism of water diffusion into noncrosslinked and ionically crosslinked chitosan membranes," Progress on Chemistry and Application of Chitin and its Derivatives, vol. 2012, pp. 59-66, 2012.

[27] A. R. Khare and N. A. Peppas, "Swelling/deswelling of anionic copolymer gels," Biomaterials, vol. 16, no. 7, pp. 559-567, 1995.

[28] W.-C. Lin, D.-G. Yu, and M.-C. Yang, "pH-sensitive polyelectrolyte complex gel microspheres composed of chitosan/ sodium tripolyphosphate/dextran sulfate: swelling kinetics and drug delivery properties," Colloids and Surfaces B: Biointerfaces, vol. 44, no. 2-3, pp. 143-151, 2005.

[29] K. V. Ranga Rao, K. P. Devi, and P. Buri, "Cellulose matrices for zero-order release of soluble drugs," Drug Development and Industrial Pharmacy, vol. 14, no. 15-17, pp. 2299-2320, 1988.

[30] D. L. Munday and P. J. Cox, "Compressed xanthan and karaya gum matrices: hydration, erosion and drug release mechanisms," International Journal of Pharmaceutics, vol. 203, no. 1-2, pp. 179-192, 2000.

[31] D. Yiamsawas, W. Kangwansupamonkon, O. Chailapakul, and S. Kiatkamjornwong, "Synthesis and swelling properties of poly[acrylamide-co-(crotonic acid)] superabsorbents," Reactive and Functional Polymers, vol. 67, no. 10, pp. 865-882, 2007.

[32] Z. Y. Ding, J. J. Aklonis, and R. Salovey, "Model filled polymers. VI. Determination of the crosslink density of polymeric beads by swelling," Journal of Polymer Science Part B: Polymer Physics, vol. 29, no. 8, pp. 1035-1038, 1991.

[33] E. Karadag, D. Saraydin, and O. Güven, "Influence of some crosslinkers on the swelling of acrylamide-crotonic acid hydrogels," Turkish Journal of Chemistry, vol. 21, no. 3, pp. 151-161, 1997.

[34] A. Thakur, R. K. Wanchoo, and P. Singh, "Structural parameters and swelling behavior of phsensitive poly(acrylamide-coacrylic acid)hydrogels," Chemical and Biochemical Engineering Quarterly, vol. 25, no. 2, pp. 181-194, 2011.

[35] Y. Li, X. Chen, Y. Liu, J. Lu, and Y. Zhao, "Synthesis and characterization of poly(aspartic acid) composite hydrogels with inorganic MCM-41 cross-linker," Iranian Polymer Journal, vol. 23, no. 12, pp. 907-916, 2014.

[36] Y.-T. Xie and A.-Q. Wang, "Preparation and swelling behaviour of chitosan-g-poly(acrylic acid)/muscovite superabsorbent composites," Iranian Polymer Journal, vol. 19, no. 2, pp. 131-141, 2010.

[37] Y. Wu, J. Zhou, C. Ye, H. Sun, and R. Zhao, "Optimized synthesis of lignosulphonate-g-poly(acrylic acid-co-acrylamide) superabsorbent hydrogel based on the taguchi method," Iranian Polymer Journal, vol. 19, no. 7, pp. 511-520, 2010. 

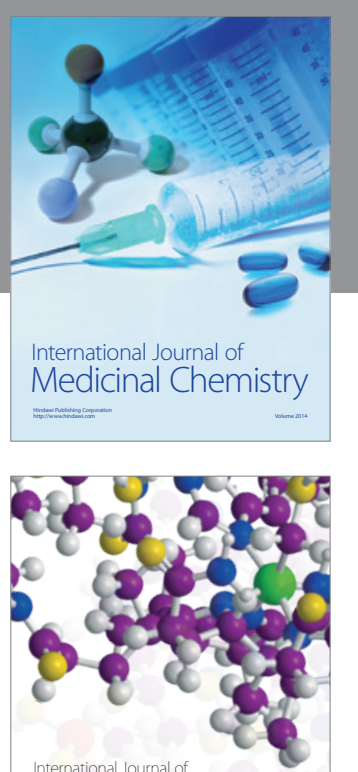

Carbohydrate Chemistry

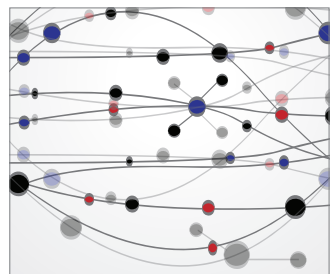

The Scientific World Journal
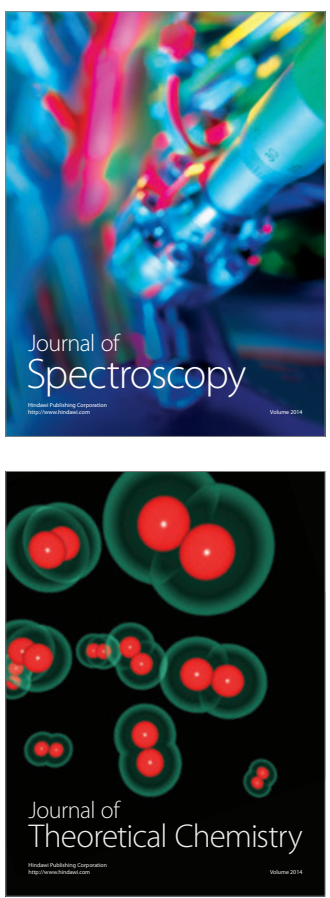
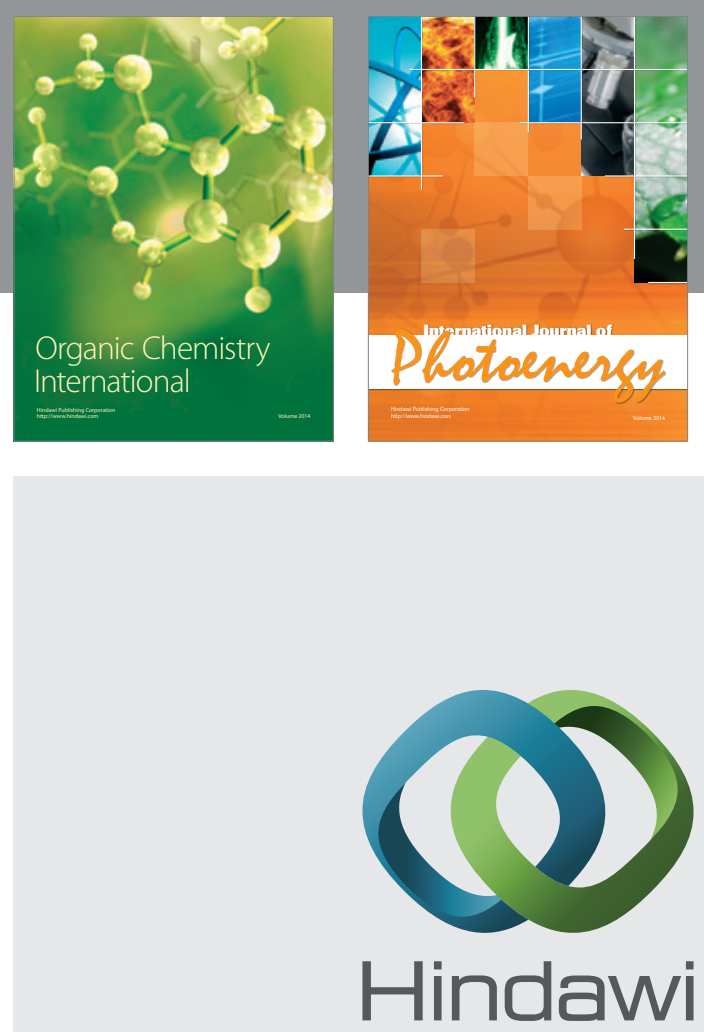

Submit your manuscripts at

http://www.hindawi.com

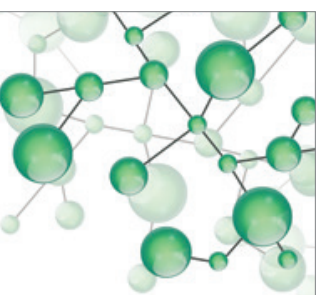

International Journal of

Inorganic Chemistry

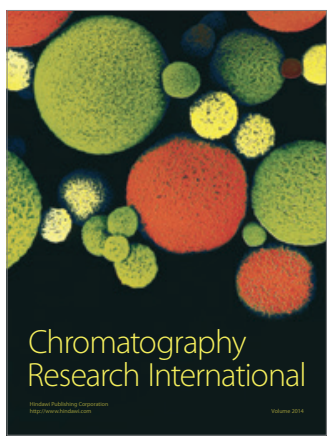

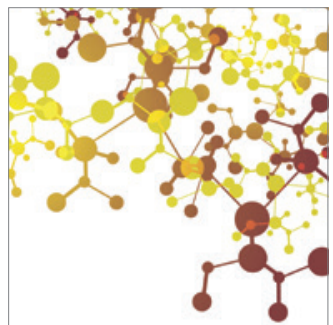

Applied Chemistry
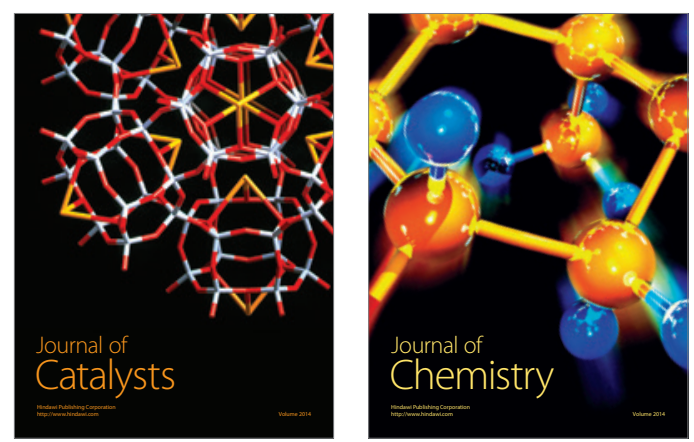
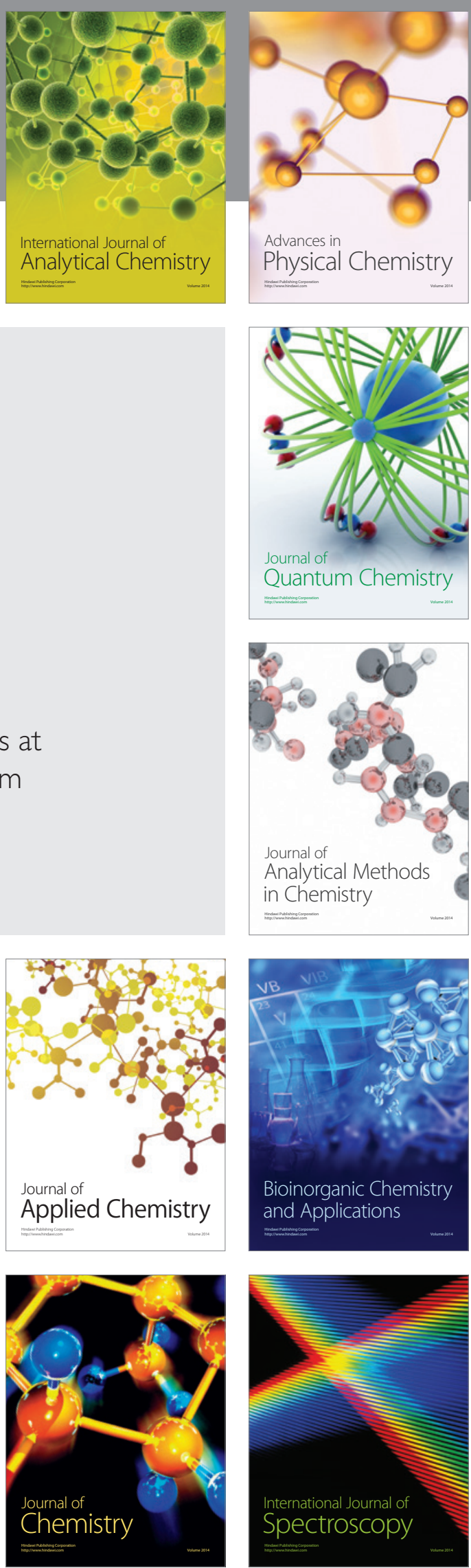